\title{
Determination of optimal blowing-to-suction flow ratio in mechanized excavation face with wall-mounted swirling ventilation using numerical simulations
}

\author{
Runze Gao ${ }^{1}$ Pengfei Wang ${ }^{2,3}$ (D) $\cdot$ Yongjun $\mathrm{Li}^{2} \cdot$ Ronghua $\mathrm{Liu}^{1,3}$
}

Received: 12 March 2020/Revised: 24 April 2020/Accepted: 26 November 2020/Published online: 7 January 2021

(C) The Author(s) 2021

\begin{abstract}
Wall-mounted swirling ventilation is a new type of system in mechanized excavation faces with a dust suppression performance that is closely related to the blowing-to-suction flow ratio. Physical and simulation models were developed according to the No. C103 mechanized excavation face in the Nahe Coal Mine of the Baise Mining Bureau, Guangxi Province to optimize the blowing-to-suction flow ratio for wall-mounted swirling ventilation. Both the $k-\varepsilon$ turbulence model and the discrete phase model were utilized to simulate airflow field structures and dust concentration distribution patterns at various blowing-to-suction flow ratios. The results suggest that higher blowing-to-suction flow ratios increase the airflow field disturbance around the working face and weaken the intensity of the axial air curtain. On the other hand, both the intensity of the radial air curtain and the dust suppression effect are enhanced. At a blowing-tosuction flow ratio of 0.8 , the wall-mounted swirling ventilation system achieved the most favorable dust suppression performance. Both the total dust and respirable dust had their lowest concentrations with maximum efficiencies of reducing both types at $90.33 \%$ and $87.16 \%$, respectively.
\end{abstract}

Keywords Mechanized excavation face $\cdot$ Wall-mounted swirling ventilation $\cdot$ Blowing-to-suction flow ratio $\cdot$ Airflow field · Dust

\section{Introduction}

As the national demand for underground mineral resources has continued to grow in recent years, both the mining intensity and mechanized degree have also increased. Consequently, dust production in a mechanized excavation face has dramatically increased, which causes the gradual

Pengfei Wang

pfwang@sina.cn

1 School of Resource, Environment \& Safety Engineering, Hunan University of Science \& Technology, Xiangtan 411201, China

2 Work Safety Key Lab On Prevention and Control of Gas and Roof Disasters for Southern Coal Mines, Hunan University of Science \& Technology, Xiangtan 411201, China

3 Hunan Provincial Key Laboratory of Safe Mining Techniques of Coal Mines, Hunan University of Science \& Technology, Xiangtan 411201, China deterioration of operational environments (Zhou et al. 2019a; Tao et al. 2018; Liu et al. 2019a; Yao et al. 2020; Wang et al. 2019a). High-concentrations of dust around the mechanized excavation face inevitably increase the probability of pneumoconiosis and reduce the visibility of workers. More seriously, this may lead to multiple safety accidents, such as mine explosions, which seriously threaten safe production and miner health (Zhou et al. 2019b; Ma et al. 2018; Wang et al. 2019b, c). According to field measurement results, without adopting dust suppression measures, the dust concentration in a mechanized excavation face can reach as high as $1200-1500 \mathrm{mg} / \mathrm{m}^{3}$. Even with effective measures, the operating environment in many mechanized excavation faces is still unsatisfactory and the maximum dust concentration in the area of the roadheader driver reaches up to $900 \mathrm{mg} / \mathrm{m}^{3}$ (Peng et al. 2019; Liu et al. 2019b; Zhang et al. 2018; Wang et al. 2019d). The National Safety and Health Commission of 
China reported 23,497 new occupational cases in its Statistical Report on Occupational Diseases in 2018. Among the reported cases, 19,468 were pneumoconiosis at $82.85 \%$ of the total number of cases. From the perspective of industry field distributions, the reported pneumoconiosis cases appeared primarily in the coal and non-ferrous metal mining industries. Among these pneumoconiosis cases, the reported number in the mining industry was approximately $40 \%$ of the total number of reports (Wang et al. 2018a, b, 2019e, f).

Long-forced-short-extracted ventilation is a common dust suppression method in mechanized excavation faces (Liu et al. 2019c; Wang et al. 2018a, b; Tan et al. 2020; Wang et al. 2019g). However, this technique cannot effectively control dust production at the mechanized excavation face. Specifically, such systems cannot form complete dust-suppression air curtains; thus, the produced dust cannot be blocked within the restricted area of the tunneling end. Therefore, a large amount of dust diffuses towards the operational region of the driver while little is taken in by the dust-removal fan (Jiang et al. 2015; Wang et al. 2007; Nie et al. 2018; Hua et al. 2018). In early studies, western scholars added a wall-mounted air cylinder to the traditional long-forced-short-extraction ventilation system to create an airflow barrier ahead of the roadheader driver. This barrier prevents dust from dispersing outwards from the working face, which blocks the produced dust from the boring process and finally discharges it via the dust removal fan (Wang et al. 2002). German scientists first developed wall-mounted air cylinders and applied them in tunneling projects. The wall-mounted swirling ventilation was confirmed to effectively block dust diffusion as produced in tunneling processes (Zhou et al. 2017). At the end of the 20th century, the KOMAG Mining Mechanization Center in Poland provided enhanced performances of wallmounted air cylinders by integrating a local fan for dust control and suppression (Qin et al. 2011; Wang et al. 2015). Furthermore, the research teams led by Aminossadati and Parra numerically simulated the airflow organization of a wall-mounted air cylinder under different conditions (Aminossadati et al. 2008). The same groups also validated and estimated the simulation model through experiments to provide reliable theoretical guidance ( $\mathrm{Li}$ et al. 2016; Toraño et al. 2011).

The wall-mounted swirling ventilation technique was initially applied in China at the end of the 1990s. Chinese scholars made substantial theoretical investigations and technical improvements based on foreign application experiences. Fu et al. (2008) numerically analyzed the airflow field in a mechanized excavation face with a wallmounted swirling ventilation system using computational fluid dynamics (CFD). The results were compared with the airflow field under conventional long-forced-short-exhaust ventilation conditions. The comparative analysis indicates that swirling ventilation not only restricts dust within limited areas around the boring end and enhances the dustcollecting efficiency of the dust removal system but also causes the gas to disperse away from the roof and stops it from accumulating at the boring end. Cheng et al. (2016) numerically simulated the dust suppression performance of the wall-mounted ventilation technique in a mechanized excavation face, where the numerical analysis results were verified based on on-site measurements. It was revealed that the formed radial swirling airflow can effectively block the roadway. Additionally, a dust-suppression air curtain was formed ahead of the roadheader driver that pointed towards the heading end. Their measurement results revealed that the utility of the wall-mounted swirling ventilation can significantly reduce the dust concentration in the operating region of the mechanized excavation face and achieve a dust suppression efficiency as high as $81.72 \%$. Furthermore, Nie et al. (2016) reported a novel, light, wall-attached air cylinder made from polymer materials and analyzed the effects of the air suction capacity on the dust suppression performance by varying the air capacity of the dust removal fan. They concluded that a greater blowing-to-suction flow ratio gives a higher dust suppression performance. This caused the dust to diffuse to a smaller range and decreased its concentration around the roadheader driver. Based on simulation results and onsite tests, Liu et al. (2018, 2019a, b, c, d) and Yin et al. (2019) reported that the dust suppression performance is also impacted by the installation location of the air curtain generator. As the air curtain generator moves farther from the heading end, the radial air curtain has a worse dust-barrier performance while the axial air curtain has an enhanced dust-blocking performance. The best installation position of the air curtain generator was recommended where the diffusion range of dust is the smallest and the dust reduction efficiency is the highest.

The blowing-to-suction flow ratio is a key factor in the dust suppression performance of wall-mounted swirling ventilation systems at the mechanized excavation face. In studies that examined the effects of the blowing-to-suction flow ratio on the dust suppression performance, the air blowing capacity is generally fixed while the air suction capacity is varied. A well-accepted opinion is that a smaller blowing-to-suction flow ratio is beneficial to dust suppression. However, related research on dust suppression effects at varying air blowing capacities is still unclear. Currently, field applications rely heavily on subjective experiences to set the air blowing capacity. As a result, the dust suppression performance in practice is significantly limited. This study first numerically analyzes the performance of the ventilation system and then validates the effectiveness of the established mathematical model 
through numerical simulations using similarity tests. Thus, adjusting the air capacity of the forced cylinder allows examining the effects of the blowing-to-suction flow ratio of the wall-mounted swirling ventilation system on the airflow field and dust suppression performance in a mechanized excavation face. Finally, the optimal blowingto-suction flow ratio is determined. This study provides theoretical direction for practical applications of the proposed ventilation mode.

\section{Development of physical and mathematical models}

The physical model was developed according to the No. C103 mechanized excavation face at the Nahe Coal Mine in the Baise Mining Bureau, Guangxi Province. The working face had a rectangular cross-section with dimensions of $4.5 \mathrm{~m} \times 3.2 \mathrm{~m}$ and an area of $14.4 \mathrm{~m}^{2}$. The EBZ230 roadheader was used for heading. The maximum dust concentration in the working face was $991 \mathrm{mg} / \mathrm{m}^{3}$. The relative gushing of $\mathrm{CH}_{4}$ and $\mathrm{CO}_{2}$ were 1.17 and 1.69 $\mathrm{m}^{3} / \mathrm{t}$, respectively, and the concentrations of poisonous and pernicious gases were extremely low.

\subsection{Construction of physical model}

The physical model was constructed using a rectangular tunnel in the front of the heading face with a length of $30 \mathrm{~m}$. The full-scale physical model consisted primarily of the tunnel and some main equipment, including air cylinders, a roadheader, and a belt conveyor scaled at 1:1. For convenient simulations, the standard simplified model was developed for the tunnel. Figure 1 shows the developed model for the studied wall-mounted swirling ventilation system.

From Fig. 1, the tunnel was $4.5 \mathrm{~m}$ wide, $3.2 \mathrm{~m}$ high, and $30 \mathrm{~m}$ long. The front end of the roadheader was $3 \mathrm{~m}$ ahead of the heading face, and the driver of the roadheader was $5 \mathrm{~m}$ ahead of the heading face. The exhaust cylinder was installed on the roadheader at a horizontal height of $1.6 \mathrm{~m}$ at the tunnel center. The air inlet of the exhaust cylinder was $3 \mathrm{~m}$ ahead of the heading face. The forced air cylinder was tightly pressed to the left side of the tunnel at a horizontal height of $2.7 \mathrm{~m}$. The air outlet of the forced cylinder was $5 \mathrm{~m}$ away from the heading face. Furthermore, three strip-shaped air-out slits with dimensions of $1.6 \mathrm{~m}$ $\times 0.06 \mathrm{~m}$ were arranged outside the forced air cylinder with a spacing of $3.4 \mathrm{~m}$. The origin of the coordinate system and the direction of the axes are shown in Fig. 1.

The meshes were generated using the ICEM CFD software, as shown in Fig. 2. In the model, the computational domain was set to the fluid domain, which was set to air in Fluent. Tetrahedral meshes were used to grid the calculation regions. The size of the global meshes was optimized to $0.3 \mathrm{~m}$, the size of the local meshes for the three stripshaped air-out slits was set to $0.02 \mathrm{~m}$, and the size of the local meshes for the two round air-out slits was set to $0.05 \mathrm{~m}$. There were $1,071,159$ meshes generated for the tunnel model.

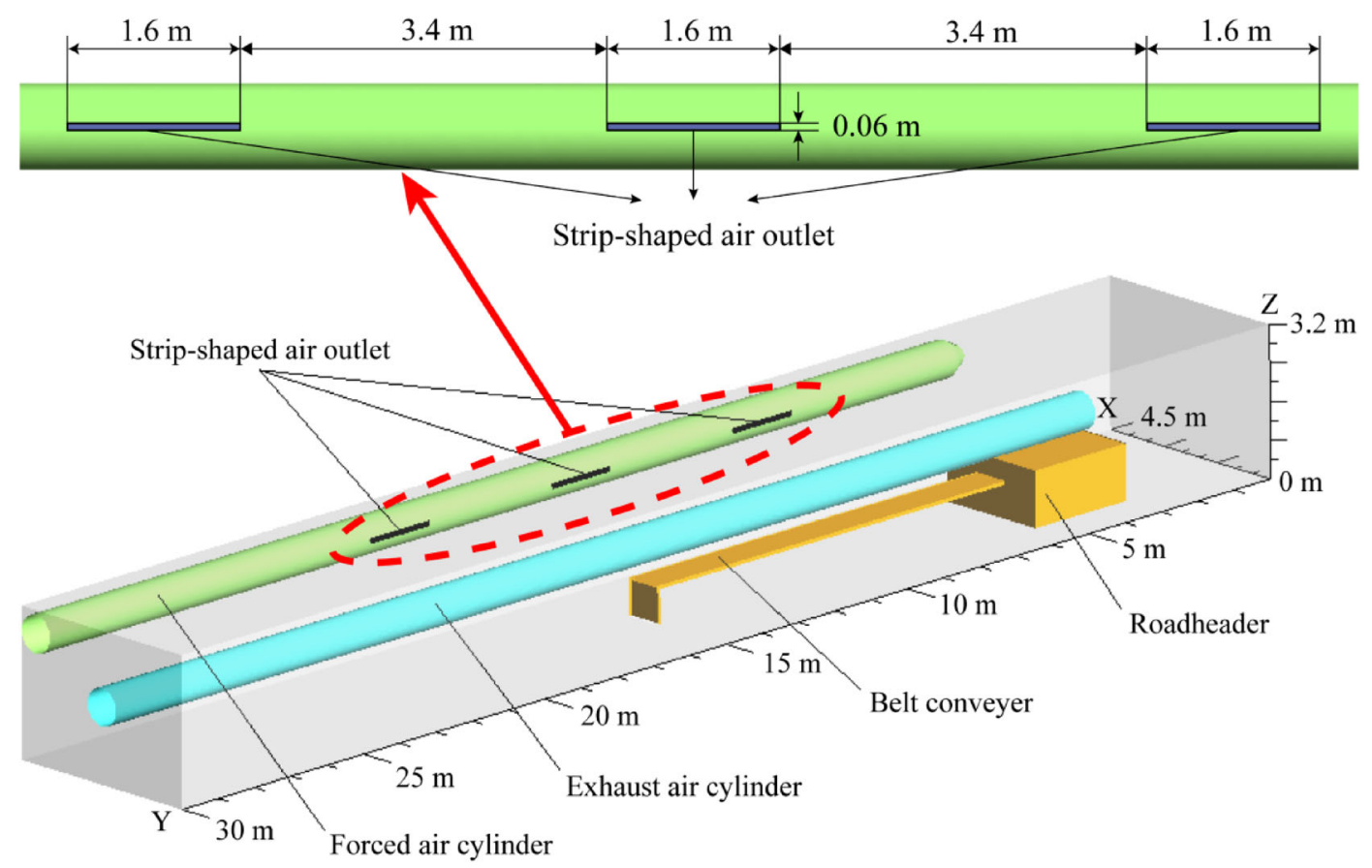

Fig. 1 Physical model of the tunnel with a wall-mounted swirling ventilation system 


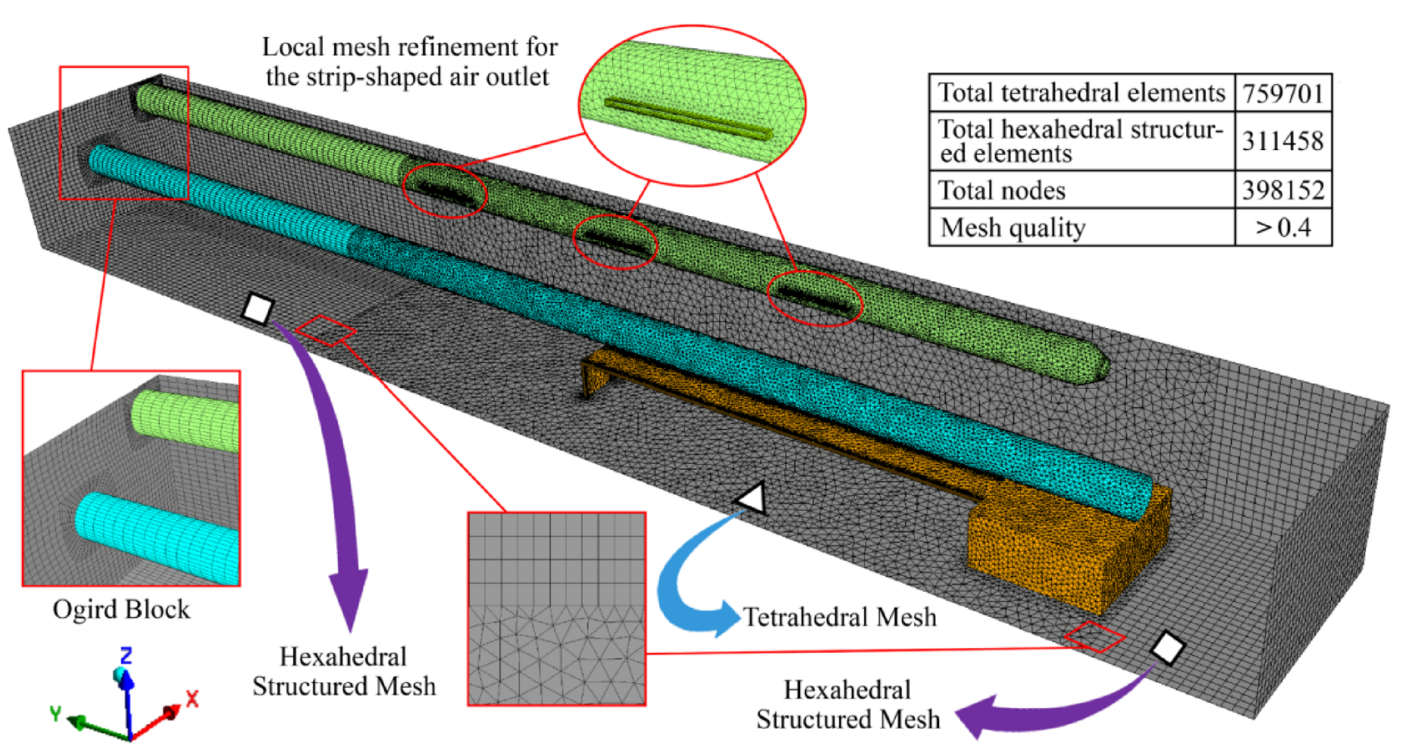

Fig. 2 Physical model of the roadway in the wall-mounted swirling ventilation and the generated meshes

When using the ICEM CFD software, the 'Element Metrics' was used to assess the mesh quality. When the 'Element Metrics' is closer to 1, the meshes have a better quality (Widiatmojo et al. 2015; Van den Berg et al. 2011; Wang et al. 2019h). Figure 3 shows the distribution of the generated meshes with different 'Element Metrics' values. For the model, the 'Element Metrics' of the meshes ranged from 0.45 to 0.95 and were greater than 0.45 for $99.41 \%$ of meshes $(1,064,824$ meshes). Moreover, the roadway was completely modeled using tetrahedral meshes that can fill the fluid domain, which indicates the generated meshes can meet the requirements of airflow-dust numerical simulations (Goldasteh et al. 2013; Zhang et al. 2016; Parra et al. 2006).

\subsection{Grid independence verification}

It is necessary to ensure the independence of the simulation results and the number of grids. The main focus of the simulations is the diffusion of pollutants at different installation distances. Thus, the dust concentration at the driver position $(3,5$, and $1.6 \mathrm{~m})$ of the roadheader was selected for independent verification. The results are shown in Fig. 4.

It can be found from Fig. 4 that when the number of grids increases from 500,000 to 3 million, the dust concentration at the driver gradually stabilizes. When the number of grids increases to 1 million, the grid number has little effect on the results. To ensure the accuracy of the simulation results and a higher calculation efficiency, it is considered that the simulation results are independent of the number of grids when above 1 million, so 1.07 million was taken as the number of calculation grids.

\subsection{Construction of mathematical model}

The Fluent software was used for the simulation analyses in this study. The airflow was treated as a continuous phase while dust particles were treated as a discrete phase. The $k$ $\varepsilon$ model in Euler coordinates was utilized to express the airflow motion, while the discrete phase model (DPM) under Lagrangian coordinates was utilized to express dust particle motion (Liu et al. 2019e; Wang et al. 2019i). In addition, the Semi-Implicit Method for Pressure-Linked Equations (SIMPLE) module was applied in the simulations.

Analyzing the wall-attached swirling ventilation airflow field in the fully mechanized excavation face shows that a cylindrical jet was ejected from the front end of the air supply cylinder. Meanwhile, airflow was ejected from the strip-shaped air-out slits, which was then rotated because of the wall attachment effect and finally showed helical motion under the action of the suction airflow at the front end. According to related literature, the Realizable $k-\varepsilon$ model can accurately predict the divergence ratio of the cylindrical jet and has been used to effectively describe uniform shear flow with a rotating free flow of mixed-flow and boundary layer flow. Therefore, this study selected the Realizable $k-\varepsilon$ model to describe the airflow motion (Kim et al. 1997). The motion equations of airflow and dust particles have been described in related references ( $\mathrm{Li}$ et al. 2019, 2020). 


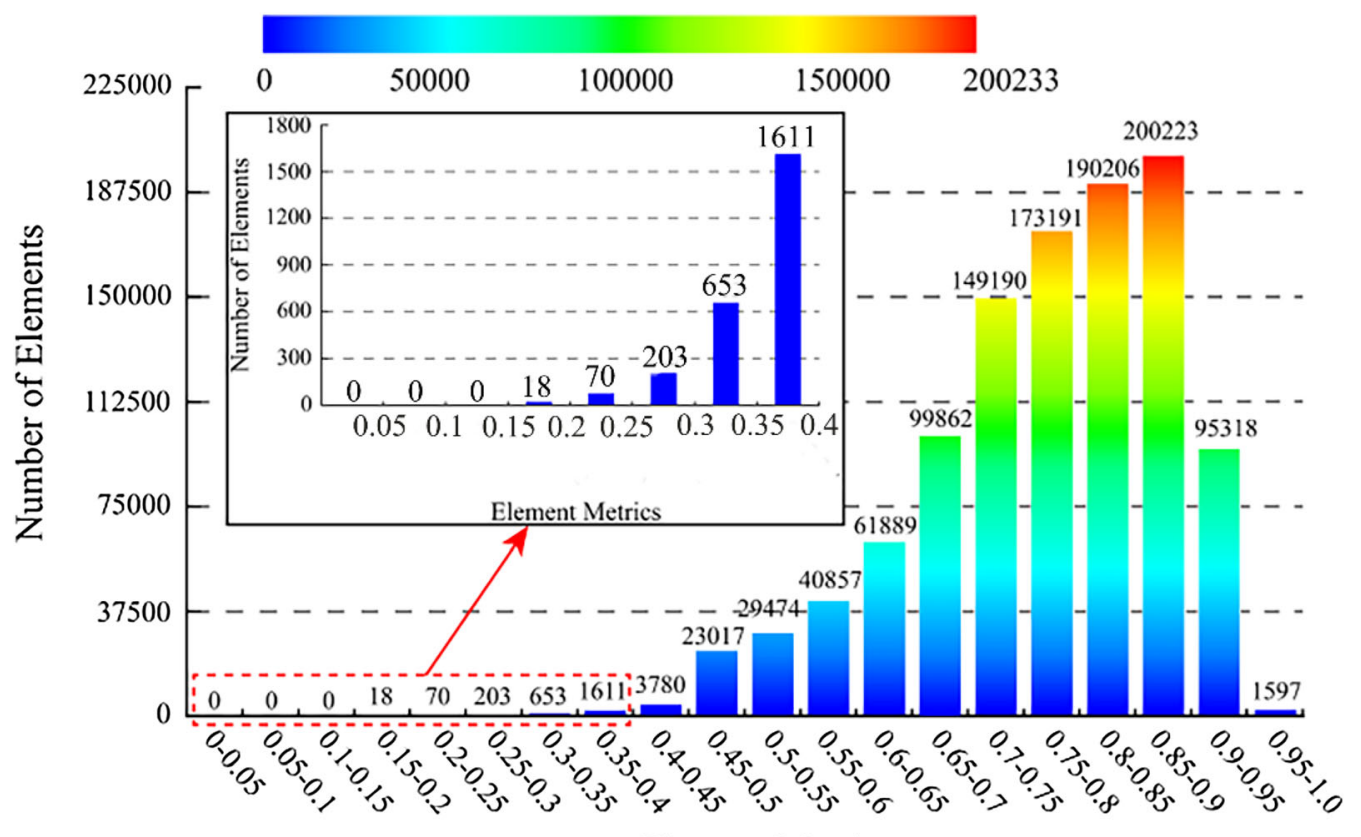

Element Metrics

Fig. 3 Trend of mesh quality versus mesh number

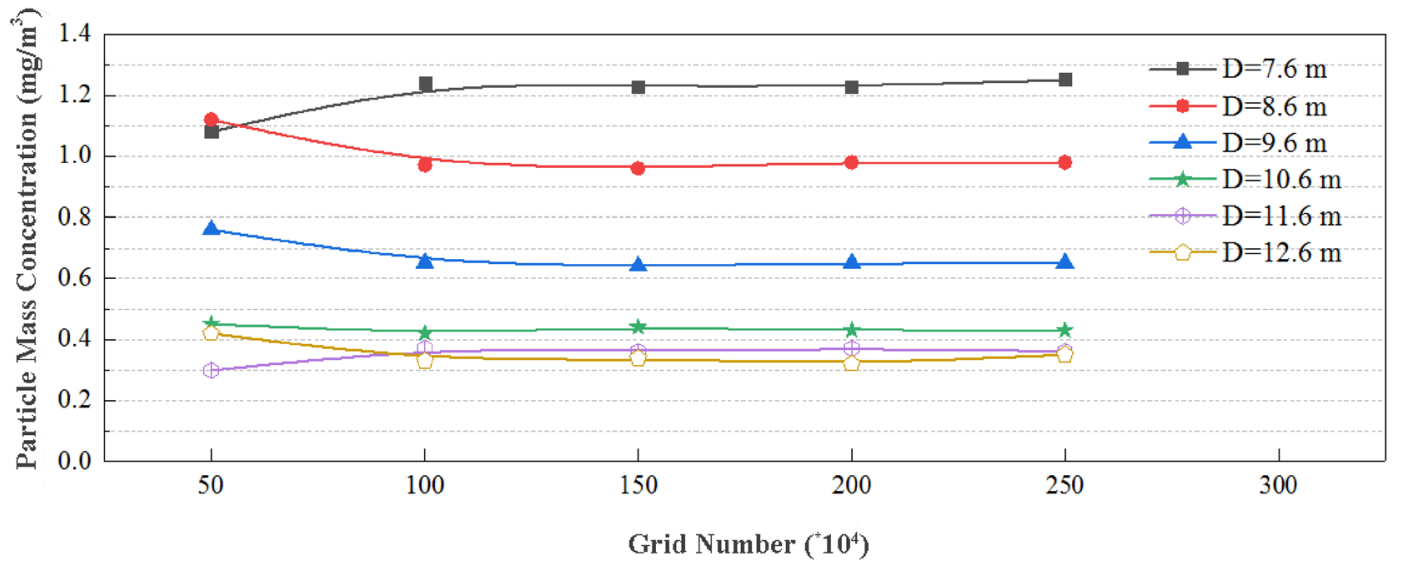

Fig. 4 Results of grid independence verification

\section{Validate effectiveness of established model}

\subsection{Design model for similarity experiments}

The experimental model was developed with a geometrical similarity ratio of $1: 8$. Thus, the rectangular tunnel in the established model was $400 \mathrm{~mm}$ high, $562.5 \mathrm{~mm}$ wide, and $4000 \mathrm{~mm}$ long. The tunnel was manufactured using transparent organic glass with the following equipment inside: forced air cylinder, exhaust air cylinder, roadheader, belt conveyer, electrostatic dedusting fan, and forced ventilation fan. The diameters of both the forced and exhaust air cylinders were $100 \mathrm{~mm}$. The installation position of the forced air cylinder was on the inner edge of the tunnel model with a height of $337.5 \mathrm{~mm}$, while the exhaust air cylinder was $200 \mathrm{~mm}$ high. Figure 5 shows a 3D view and image of the model.

\subsection{Experimental scheme}

The particle image velocimetry (PIV) system from Lavision Gmbh, Göttingen, Germany was utilized to measure the flow field inside the roadway. The PIV system consisted of two Imager Pro X $4 \mathrm{M}$ CCD cameras $(2560 \times 2560$ pixels $)$ synchronized with a double cavity $\mathrm{Nd}$ :YAG laser (frequency-doubled laser at a wavelength of $532 \mathrm{~nm}$ ). The commercial DaVis software developed by the LaVision Company was used to analyze the test data, 


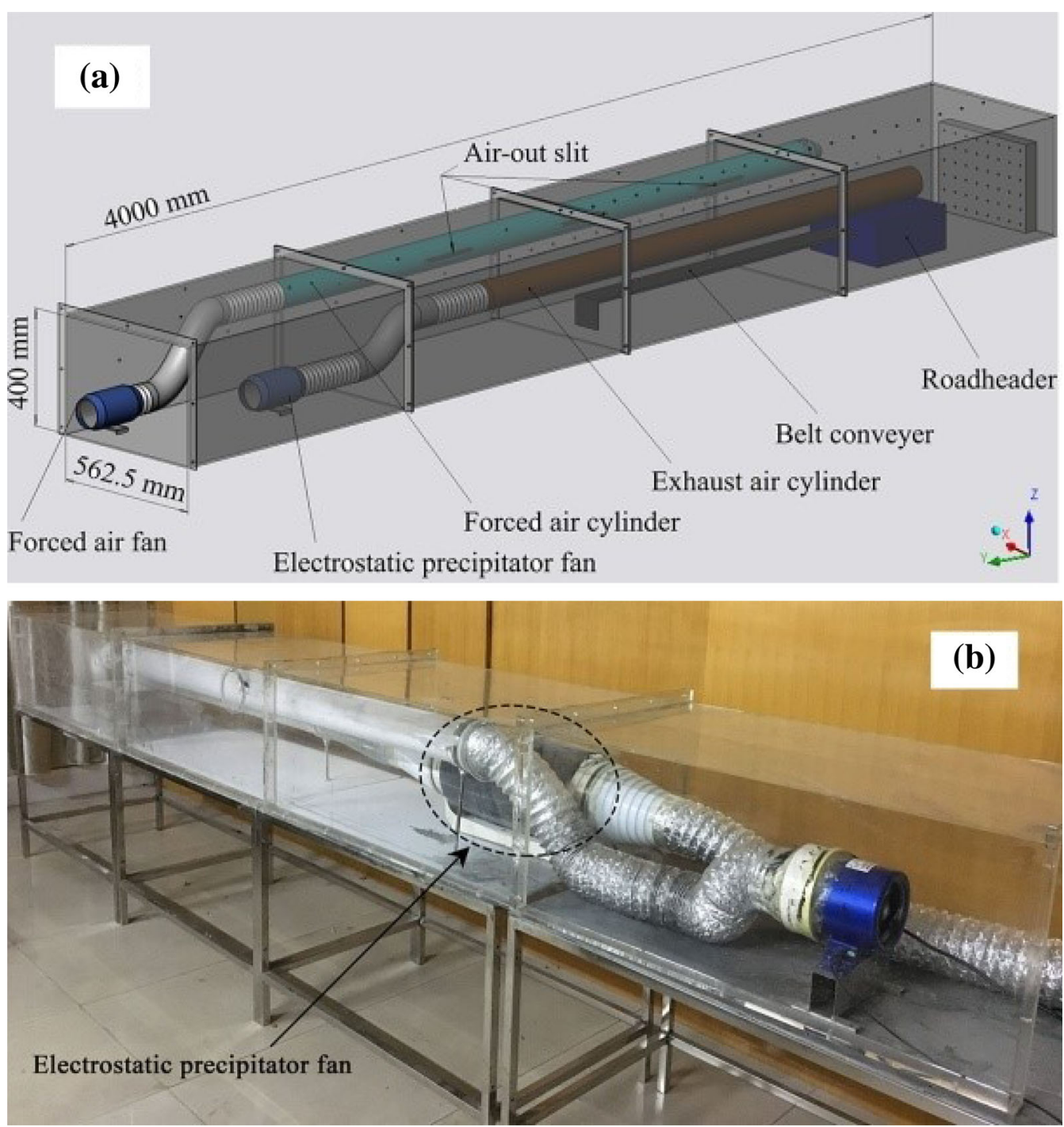

Fig. 5 a 3D view and $\mathbf{b}$ photograph of the developed model in the similarity experiment

which provided an algorithm that utilized the stereo crosscorrelation. The interrogation windows for the iterations were $32 \times 32$ pixels wide with an overlap of $50 \%$ to provide a spatial resolution of $16 \times 16$ pixels. Each PIV experiment took 30 groups of double-frame photos using CCD cameras to produce velocity profiles by averaging the associated flow fields.

The measured results from the model were verified through comparisons with the simulation results. In the experiments, a representative plane (EFGH) was used to verify the flow field. The PIV experimental system and the cross-section in the flow field tests are shown in Fig. 6. The airflow speed of the experimental model was set the same as the on-site airflow speed of the full-mechanized excavation face (Camelli et al. 2014; Hamid et al. 2013). The airflow rate of the pressure cylinder was maintained at 200 $\mathrm{m}^{3} / \mathrm{min}$ by adjusting the frequency converter of the fan, while the airflow rate of the suction cylinder was maintained at $250 \mathrm{~m}^{3} / \mathrm{min}$. In addition, adjusting the flow valve controlled the axial-radial airflow ratios of the pressure cylinder to 2:8.

At this stage, there are few studies on the similarity criteria of pollutant diffusion, which makes it challenging to obtain an accurate relationship between the laboratory model and the on-site pollutant diffusion behavior. Therefore, the similarity can be verified by analyzing the dust distribution in the roadway (Tan et al. 2015; Amyotte et al. 2009; Ciocanea et al. 2013). The experimental verification platform and associated equipment are shown in Fig. 7. The dust was produced using the German AG420 aerosol generator and transported to the working face through a circular hole at the tunneling end under forced compressed air. This process mimics dust generation from the boring machine. An FCC-25 explosion-proof dust 


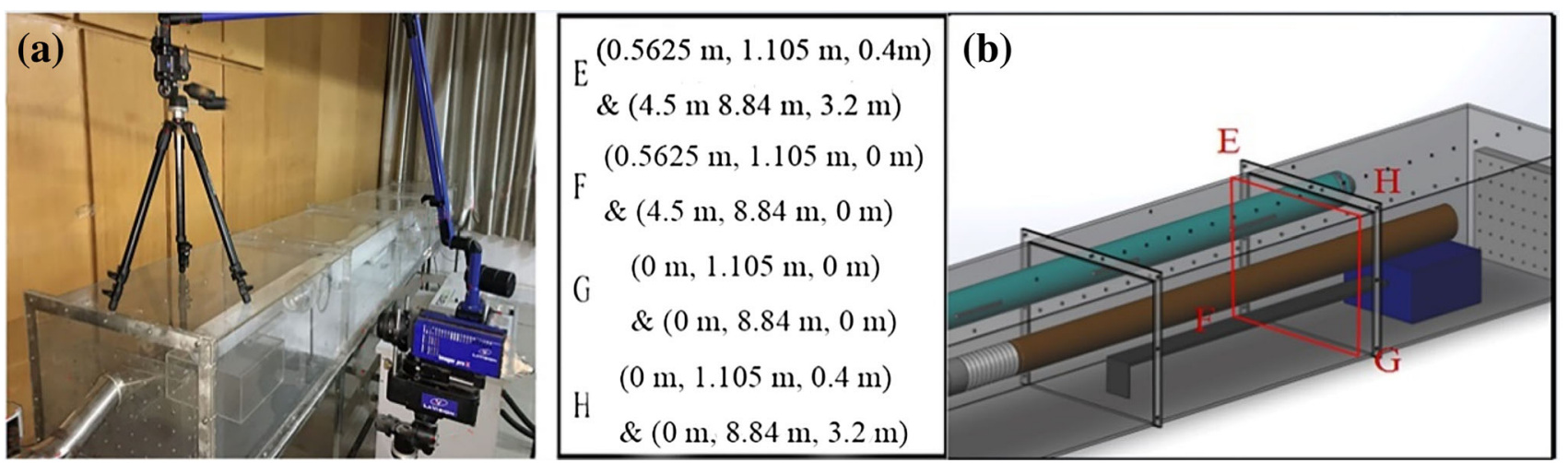

Fig. 6 PIV system and arrangement of the test cross-section: a photograph of the PIV system and $\mathbf{b}$ the representative plane

sampler was used to collect dust samples to determine the mass concentration of dust in the tunnel.

\subsection{Verification results and analyses}

\subsubsection{Airflow field}

Both the numerical analysis results and experimental measurements for the vector diagram of the flow field velocity in the test face were obtained, as shown in Fig. 8. In the figure, the pressure air cylinder is abbreviated as FAC, the exhaust air cylinder is abbreviated as EAC, and the conveyor belt is indicated as white bars. The same abbreviations and symbols are used in the subsequent sections of this paper.

From Fig. 8, the structure and velocity of the flow field for the selected test surface as obtained from numerical calculations are consistent with the measured PIV results. Four measurement points $(A, B, C$, and $D)$, on the test surface were selected for specific velocity comparisons. Validity was determined if the average error from the comparison was less than $10 \%$. Figure 9 shows that the numerical calculations and test results of the airflow velocity at the measured points match well with an average error of $6.75 \%$. Given a relative error of less than $10 \%$, the developed mathematical model is considered as able to numerically analyze the airflow field in the fully mechanized excavation face.

\subsubsection{Pollutant distribution}

Figure 10 shows the concentration distribution of dust from the numerical analyses and experimental results. The figure indicates that while the simulation and verification results diverge in absolute values, the overall trends were nearly the same. Under wall-mounted swirling ventilation, the majority of dust was concentrated close to the working face. As the measuring point was farther from the tunneling end, the dust concentration first reduced before eventually stabilizing. The analysis results suggest the numerical calculation model established in this study has a high feasibility to study the distribution patterns of pollutants and the airflow field in roadways. Thus, numerical calculations provide a guide for site pollution control in the excavation face to some extent.

\section{Numerical calculations}

The flow features and dust diffusion rules in the tunnel with a wall-mounted swirling ventilation system were investigated using Fluent at varying blowing-to-suction flow ratios. The airflow field and the effects of the blowing-tosuction flow ratio on its structural characteristics were analyzed in two regions: (1) around the heading end and (2) between the strip-shaped air-out slit and the roadheader driver. Both the radial and axial airflows were considered in the analysis. The analysis of the dust diffusion rules, variations in the migration distance of dust, and the dust concentration at the roadheader driver operating position at varying blowing-to-suction flow ratios were the primary investigations.

\subsection{Boundary conditions and parameters}

Based on the established model, the air capacity of the exhaust cylinder was converted into the airflow velocity from the air capacity requirements in the mine and the exhaust air capacity measured on-site. The airflow velocity was set in the Fluent software. At each blowing-to-suction flow ratio, the air capacity of the front surface of the forced cylinder should occupy $20 \%$ of the total forced air capacity, and the total air capacity from the three strip-shaped air-out slits should occupy the remaining $80 \%$. This paper assumes that the blowing-to-suction flow ratio is expressed as $\beta$, and the forced air capacity can be calculated from the 


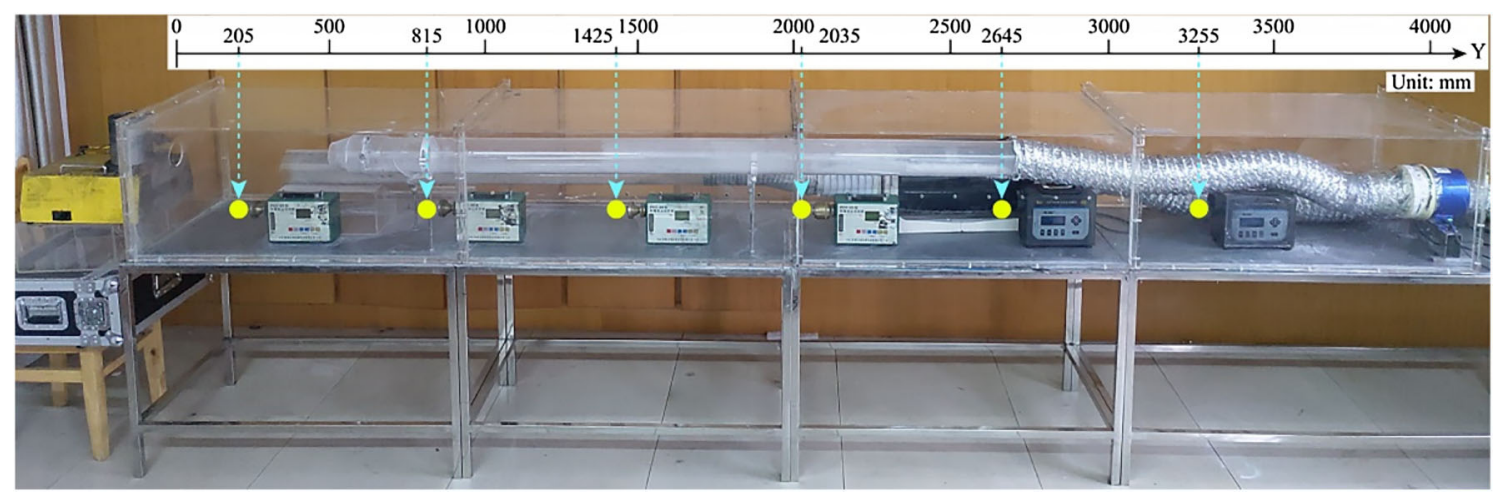

Fig. 7 Similarity verification for the experimental platform on the dust distribution in the roadway

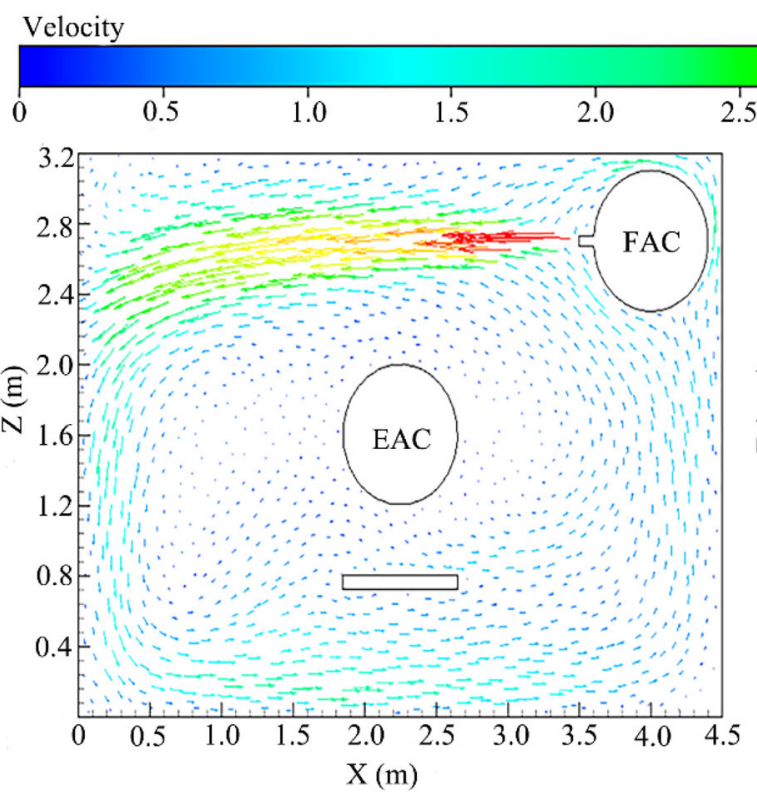

(a)

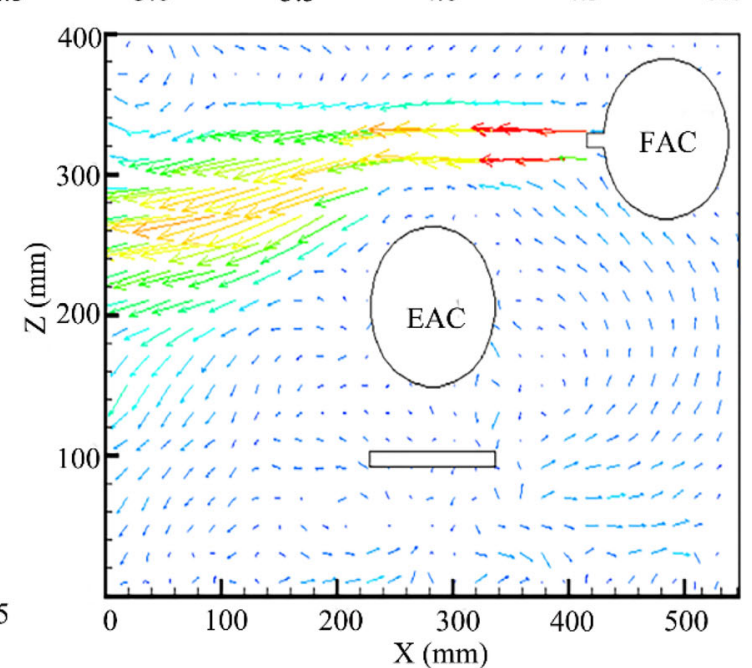

(b)

Fig. 8 Velocity vectors of the test face: a numerical simulation results and b PIV results

fixed exhaust air capacity at each $\beta$. Table 1 lists the specific parameters.

The parameters and boundary conditions of the model were set based on practical conditions for the working face. The produced dust from the source and the distribution pattern of dust particles were set based on field measurements and the laboratory analysis results. The detailed parameter settings are given in Table 2 .

\subsection{Effects of blowing-to-suction flow ratio on airflow field}

\subsubsection{Effects of blowing-to-suction flow ratio on airflow field around the heading end}

Figure 11 shows the airflow field structure in the horizontal section at a height of $2.7 \mathrm{~m}$ (z-axis) at different blowing-to-

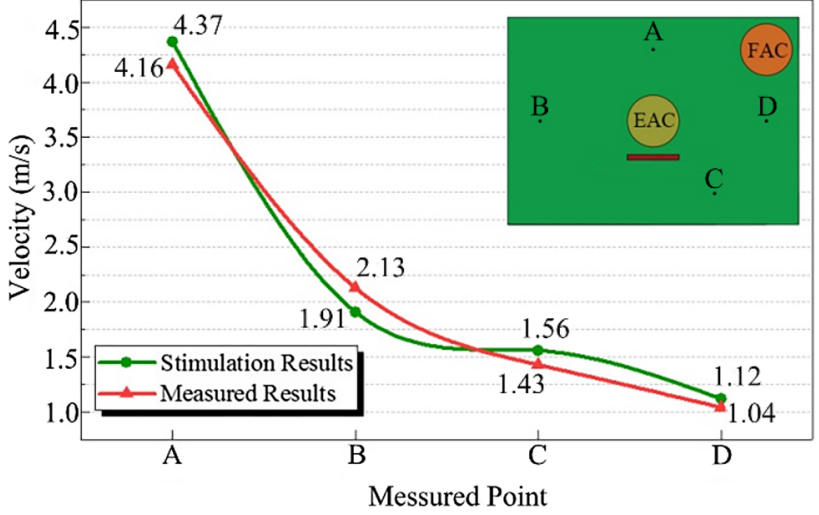

Fig. 9 Comparison results of the airflow velocity at the measured points

suction flow ratios. The airflow was split into two portions before being blown out from the forced air cylinder. One 


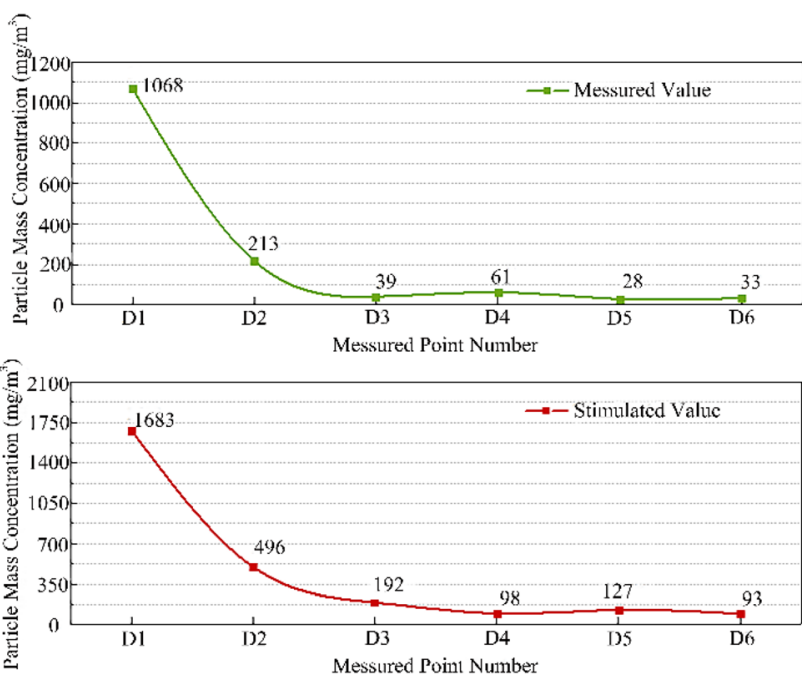

Fig. 10 Dust concentration distribution curves

portion of the airflow exited from the front face of the cylinder, which blew directly towards the working face, while the other portion exited from the strip-shaped slits inside the air cylinder. At blowing-to-suction ratios of 0.6 and 0.7 , the airflow velocity in front of the outlet of the forced cylinder was small and had a strong attenuation. The jet velocity was small at the heading face and imposed a certain disturbance on the region around the heading end. Moreover, a vortex was formed due to the exhaust airflow around the exhaust air inlet, which played a controlling role. As the blowing-to-suction flow ratio was increased to $0.9,1.0$, and 1.2 , the airflow velocity at the outlet in the front section of the forced cylinder became excessively large. As a result, the heading end experienced a more intense disturbance. Accordingly, the exhaust airflow cannot fully control the roadway, and dust was driven by some of the airflow to move outwards.

\subsubsection{Effects of blowing-to-suction flow ratio on radial airflow}

Figure 12 shows the radial airflow field structures on the section located at $Y=10 \mathrm{~m}$. At blowing-to-suction ratios of 0.6 and 0.7 , the radial airflow velocity was small and low-velocity holes were found around the exhaust air cylinder. As a result, a complete radial air curtain cannot be formed, and dust can easily escape from the low-velocity
Table 2 Main parameter settings for the boundary conditions and particle source

\begin{tabular}{|c|c|c|}
\hline Project & Definition & Parameter \\
\hline \multirow[t]{5}{*}{$\begin{array}{l}\text { Computational } \\
\text { models }\end{array}$} & Solver & $\begin{array}{l}\text { Uncoupled } \\
\text { solver }\end{array}$ \\
\hline & Viscous model & $k-\varepsilon$ \\
\hline & Energy equation & OFF \\
\hline & DPM model & $\mathrm{ON}$ \\
\hline & Inlet & Velocity inlet \\
\hline \multirow[t]{10}{*}{$\begin{array}{l}\text { Boundary } \\
\text { conditions }\end{array}$} & $\begin{array}{l}\text { Velocity of extract cylinder } \\
(\mathrm{m} / \mathrm{s})\end{array}$ & 8.29 \\
\hline & Hydraulic diameter (m) & 0.8 \\
\hline & Turbulent intensity (\%) & 3.22 \\
\hline & Outlet & Outflow \\
\hline & Shear condition of Walls & No-slip \\
\hline & Type of injection & Surface \\
\hline & Inert particles & Anthracite \\
\hline & Diameter distribution & Rosin-rammler \\
\hline & Minimum diameter (m) & $1 \times 10^{-6}$ \\
\hline & Average diameter (m) & $1.25 \times 10^{-5}$ \\
\hline \multirow{6}{*}{$\begin{array}{l}\text { Injection } \\
\text { properties }\end{array}$} & Maximum diameter (m) & $6 \times 10^{-5}$ \\
\hline & Spread parameter & 1.77 \\
\hline & Total flow rate $(\mathrm{kg} / \mathrm{s})$ & 0.0015 \\
\hline & Turbulent dispersion & $\begin{array}{r}\text { Stochastic } \\
\text { tracking }\end{array}$ \\
\hline & Number of tries & 10 \\
\hline & Time scale constant & 0.15 \\
\hline
\end{tabular}

holes. As the blowing-to-suction ratio increased to 0.8 and 0.9 , the radial air curtain became stronger, a complete radial air curtain was formed, and the holes around the exhaust air cylinder shrank. Further increases to 1.0 and 1.2 caused the radial air curtain to strengthen, and the dust and accumulated gas near the roof were adequately diluted. However, at larger flow ratios, the airflow velocity near the tunnel floor also increased, resulting in secondary dust rising from the floor. The above analysis of the structures of the radial flow fields indicates that the dust-blocking performance of the radial air curtain increases at larger blowing-to-suction flow ratios. However, at excessively large airflow velocities, the accumulated dust readily increased, which caused secondary dust pollution in the roadway. Therefore, the blowing-to-suction flow ratio should not be more than 0.9 .

Table 1 Ventilation parameter settings

\begin{tabular}{lllllll}
\hline Project & Air suction & Air inlet & & & \\
\cline { 2 - 7 } & & $\beta=0.6$ & $\beta=0.7$ & $\beta=0.8$ & $\beta=0.9$ & $\beta=1.0$ \\
\hline Air volume $Q\left(\mathrm{~m}^{3} / \mathrm{min}\right)$ & 250 & 150 & 175 & 200 & 225 & 250 \\
Air velocity $v(\mathrm{~m} / \mathrm{s})$ & 8.29 & 4.97 & 5.80 & 6.63 & 7.46 & 8.29 \\
\hline
\end{tabular}


The measurement results at three select measuring points in the above section were analyzed to study the impacts of the blowing-to-suction flow ratio on the flow field of the radial air curtain. The velocities of the measurement points were decomposed into their horizontal and vertical components. The trends of each velocity component were then obtained from the blowing-to-suction flow ratio, as shown in Fig. 13.

Figure 13 indicates that as the blowing-to-suction flow ratio increased, the velocity components in both the horizontal and vertical directions at the three measurement points had an overall increasing trend. At a relatively small blowing-to-suction flow ratio, the airflow speed at the measurement point, especially in the central region of the roadway, was small, which resulted in a weak radial airflow curtain. At higher blowing-to-suction flow ratios, the air curtain had an increased strength. At the same time, the variation law of the airflow speed at Point $B$ in Fig. 13 shows that excessively large blowing-to-suction flow ratios produce fast airflows at the bottom of the roadway (horizontal speed close to $1.5 \mathrm{~m} / \mathrm{s}$ ). In this case, secondary dust was generated and resulted in a degraded dust control effect.

Figure 14 shows the pressure distribution patterns on the section located at $Y=10 \mathrm{~m}$ at various blowing-to-suction flow ratios. At higher ratios, both the absolute pressure and the area of the negative-pressure region in the tunnel center increased. This is likely because the wall-mounted swirling intensity gradually increased for larger blowing-to-suction flow ratios, which resulted in an expansion of the negativepressure range and an increase in the negative pressure at the tunnel center. The existence of a negative pressure in the tunnel center promotes dust migration towards the

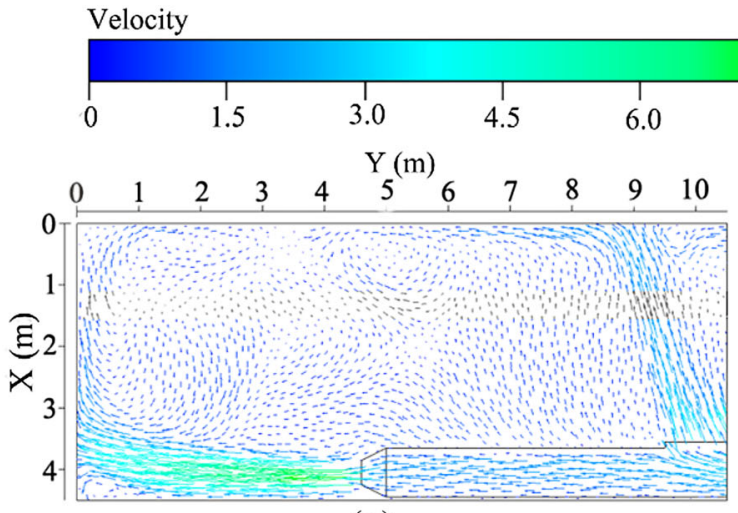

(a)

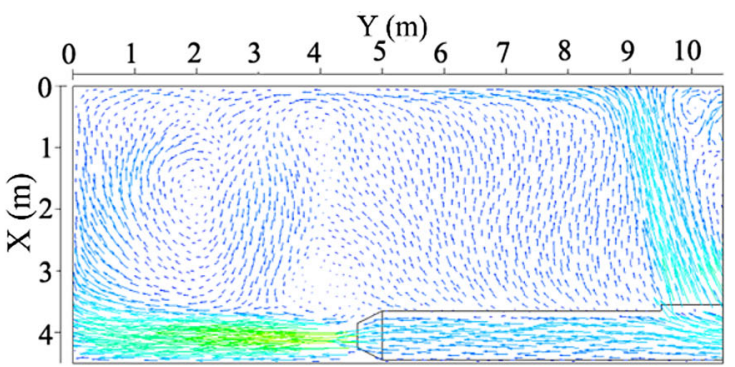

(c)

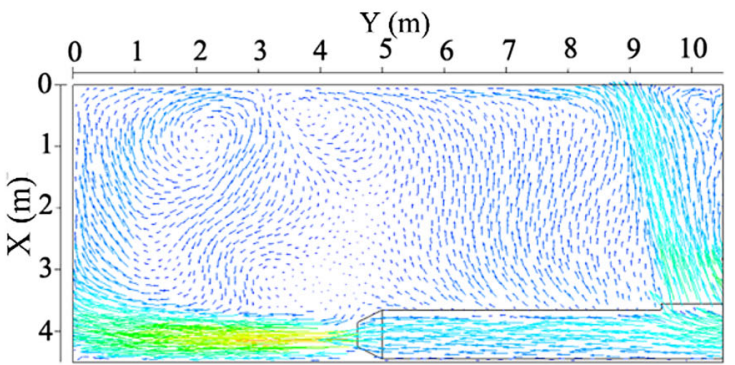

(e)

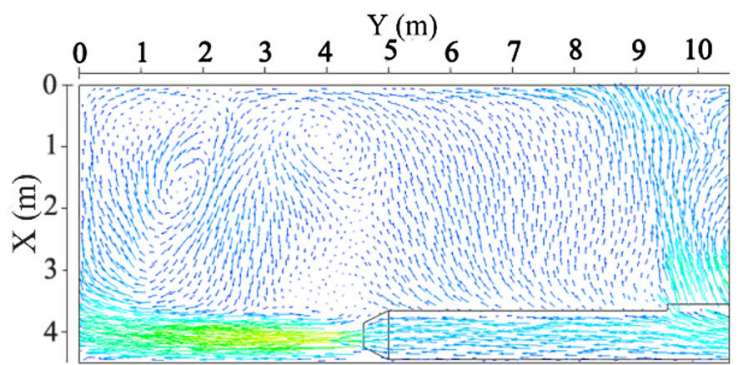

(d)

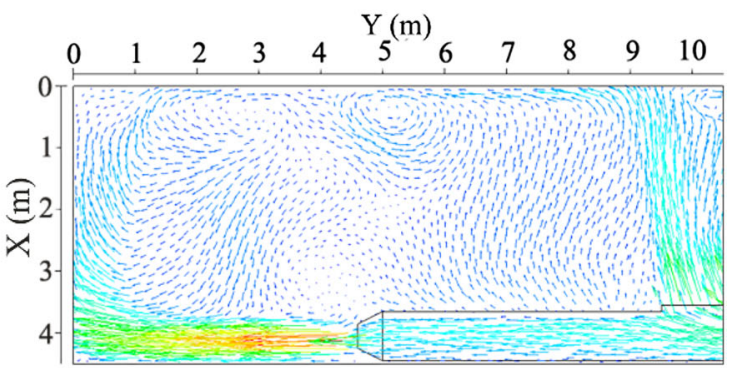

(f)

Fig. 11 Airflow field structures on the horizontal section located at $Z=2.7 \mathrm{~m}$ around the heading end at blowing-to-suction flow ratios of a $\beta=0.6, \mathbf{b} \beta=0.7, \mathbf{c} \beta=0.8, \mathbf{d} \beta=0.9$, e $\beta=1.0$, and $\mathbf{f} \beta=1.2$ 


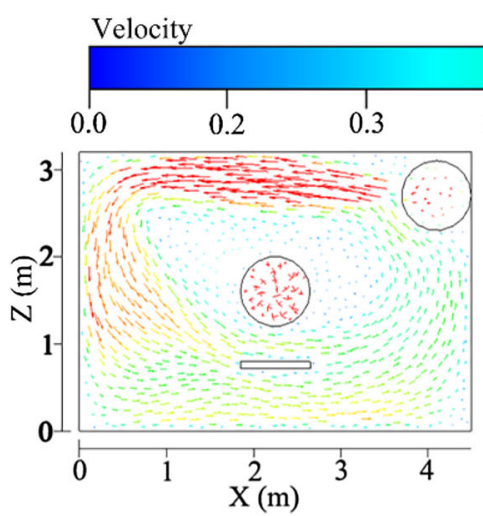

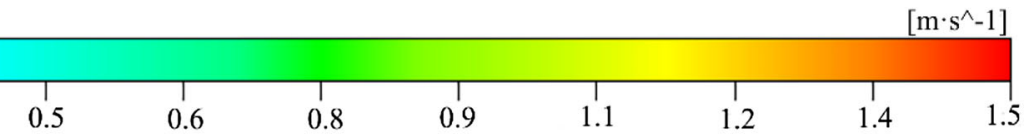
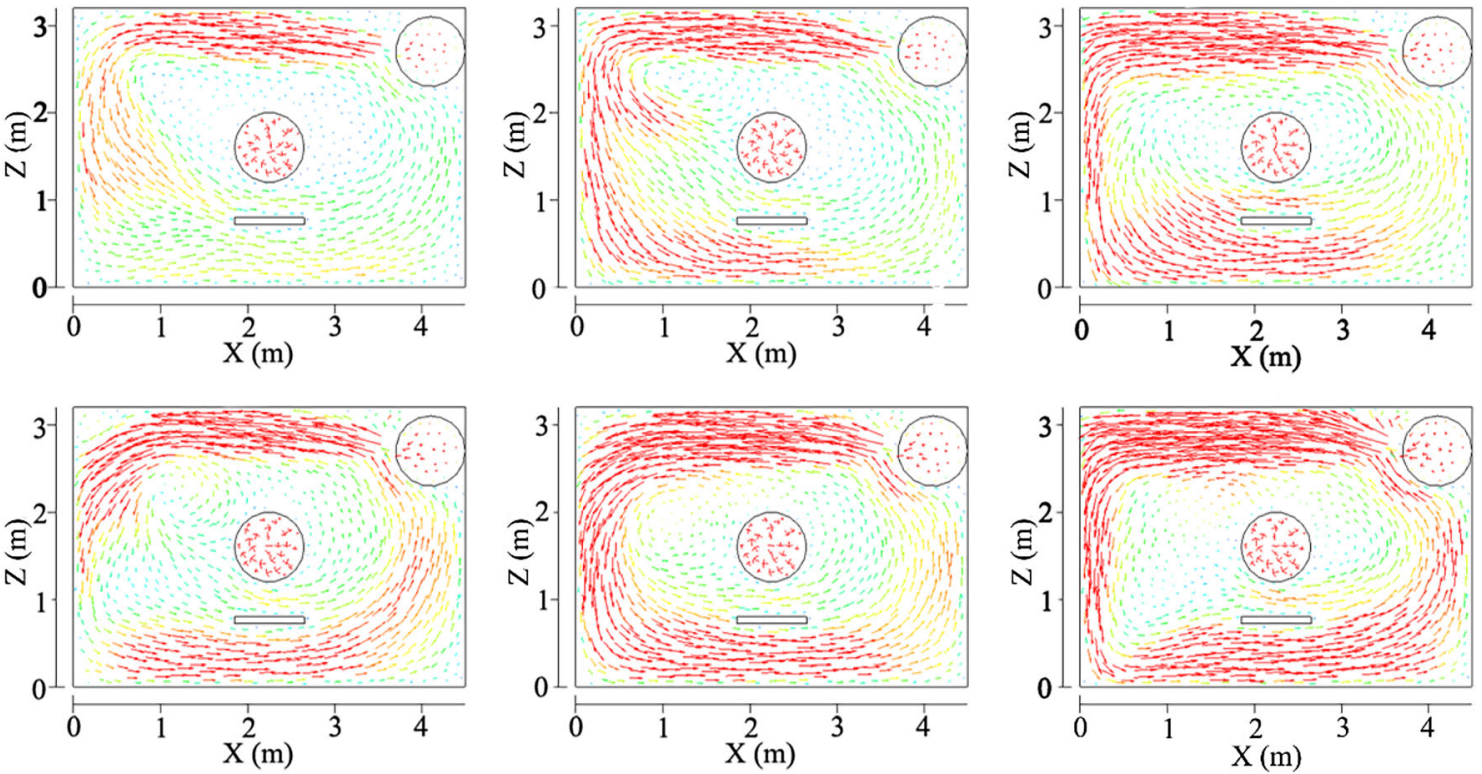

Fig. 12 Airflow field structures on the section located at $Y=10 \mathrm{~m}$ at blowing-to-suction flow ratios of $\mathbf{a} \beta=0.6, \mathbf{b} \beta=0.7, \mathbf{c} \beta=0.8, \mathbf{d} \beta=0.9$, e $\beta=1.0$, and $\mathbf{f} \beta=1.2$

tunnel center and prevents spreading, which enhances the dust-collecting effect around the exhaust inlet.

\subsubsection{Effects of blowing-to-suction flow ratio on axial airflow}

The axial airflow can effectively restrict dust within a limited range from the heading end. Three test surfaces from the roadheader driver to the first air-out slit parallel with the heading face were selected. The data statistics from Fluent for the mass flow rate and mean airflow velocity on these surfaces are shown in Fig. 15.

With the wall-mounted swirling ventilation, only a small portion of the forced airflow traveled directly towards the working face from the outlet of the forced air cylinder, while the capacity of fresh airflow was much smaller than the exhaust airflow capacity around the heading end. As a result, the fresh airflow from the back of the tunnel gradually moved towards the heading face for supply. At higher blowing-to-suction flow ratios, additional fresh airflow was transported towards the heading end, and less airflow supply was needed at the back of the tunnel; thus, both the mass flow rate and mean axial airflow velocity in the crosssection were lower. In addition, Fig. 15 shows that at higher blowing-to-suction flow ratios, both the mass flow rate and the average axial airflow velocity were reduced. Meanwhile, the intensity of the axial air curtain was weakened and the dust-blocking capability was reduced.
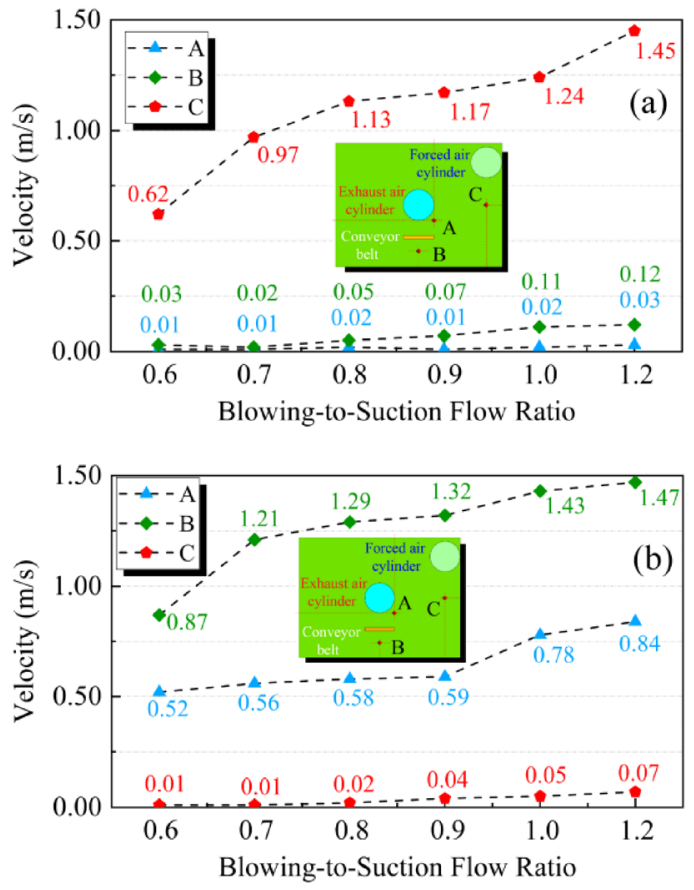

Fig. 13 Effects of the blowing-to-suction flow ratio on the velocities of the measurement points for the a horizontal and $\mathbf{b}$ vertical velocities

The dust suppression performance of wall-mounted swirling ventilation depends on the combined effects of the formed axial and radial air curtains. The above analysis suggests that at higher blowing-to-suction flow ratios, the 

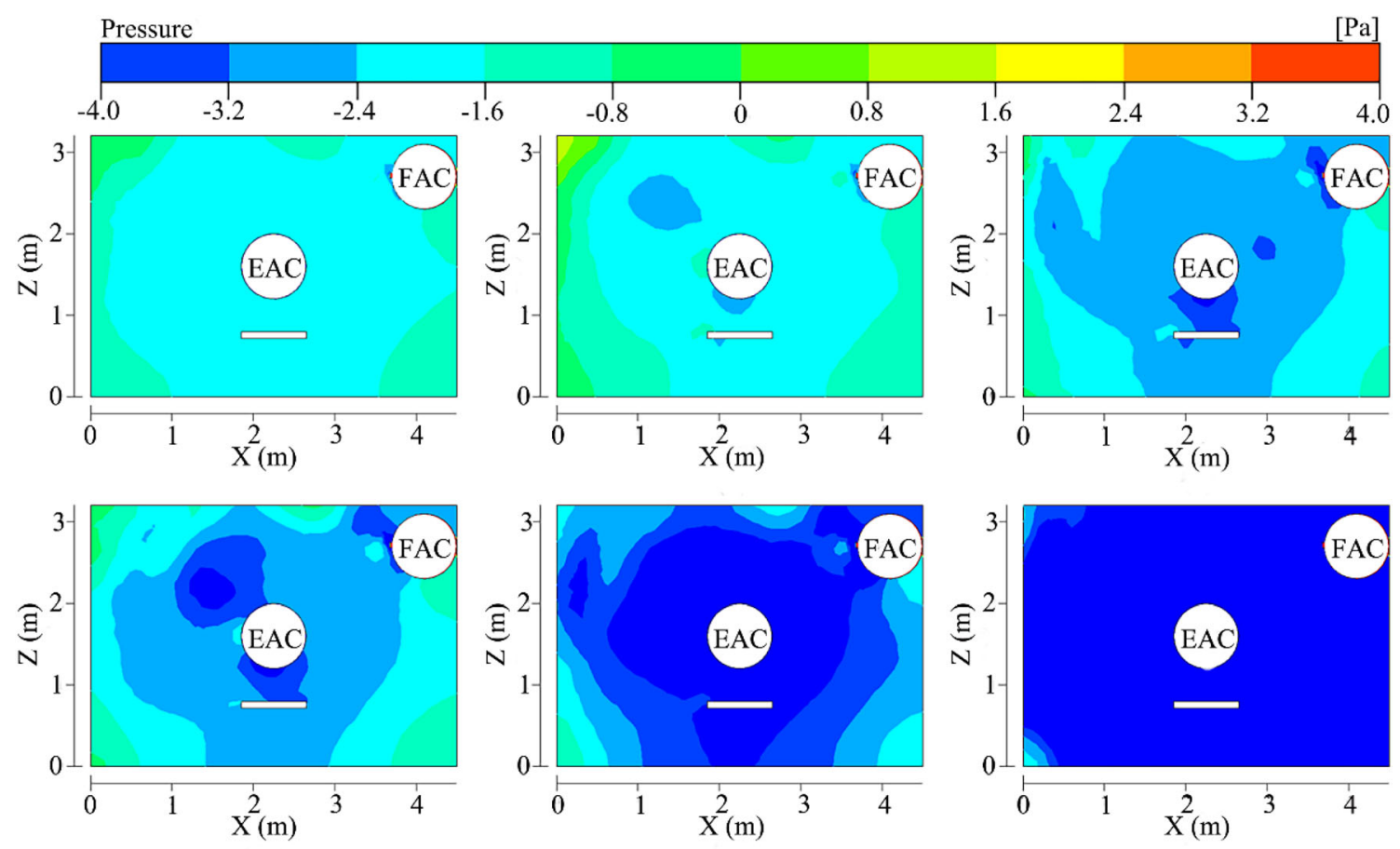

Fig. 14 Pressure field distribution patterns on the section located at $Y=10 \mathrm{~m}$ at blowing-to-suction flow ratios of a $\beta=0.6, \mathbf{b} \beta=0.7$, c $\beta=0.8, \mathbf{d} \beta=0.9$, e $\beta=1.0$, and $\mathbf{f} \beta=1.2$

flow field around the heading end experiences a stronger disturbance while the axial air curtain is weaker. On the other hand, the radial air curtain has a greater intensity and the related dust-barrier effect is improved. Therefore, an optimal blowing-to-suction flow ratio should exist to provide the strongest combined dust barrier capability for the axial and radial air curtains to yield the most favorable dust blocking performance. The dust suppression performances under various blowing-to-suction flow ratios were further analyzed to determine the optimal value.

\subsection{Effects of blowing-to-suction flow ratio on dust suppression performance}

\subsubsection{Dust concentration distribution on the cross-section at respiratory height}

The dust concentration distribution patterns in the central horizontal cross-section of the forced air cylinder at the respiratory height are shown in Fig. 16. The long tube in the middle represents the exhaust air cylinder. Different dust concentrations are marked with different colors, and the PMC on the colored axis represents particle mass concentration.

In the excavation face, the concentration distribution of dust is highly correlated with the airflow field. As shown in Fig. 16a, at a blowing-to-suction flow rate of 0.6 , the mean concentration of dust in the region 1-m ahead of the heading face was $300 \mathrm{mg} / \mathrm{m}^{3}$ with a maximum concentration of $1000 \mathrm{mg} / \mathrm{m}^{3}$. Moreover, dust particles were concentrated primarily within $5 \mathrm{~m}$ of the excavating head. Under the operating condition, the airflow velocity around the heading end was low, and vortex regions with low energies were formed. Therefore, dust particles are easily accumulated in this region. The formed radial air curtain had the lowest strength, indicating it cannot effectively block dust particles. As a result, dust easily escaped from the vortex regions and spread as far as $15 \mathrm{~m}$ to the back of the tunnel, which resulted in a high concentration of dust around the drivers.

At a blowing-to-suction flow ratio of 0.7 , the dust suppression performance was improved to a certain degree and the dust diffusion distance was shortened (Fig. 16b). The calculation results for the airflow field characteristics indicate that increasing the blowing-to-suction flow ratio enhances the intensity of the radial air curtain and forms a complete curtain. Under the combined action of the radial and axial air curtains, dust can be controlled mostly within the region in front of the driver. However, due to the small output airflow velocity in front of the air supply cylinder, the airflow has a weak disturbance on the heading face. In addition, the air exhaust inlet of the exhaust cylinder has a poor dust collection performance, which causes a high concentration of dust particles around the tunneling end. A high concentration of dust particles affects both the production safety and operational visibility. 

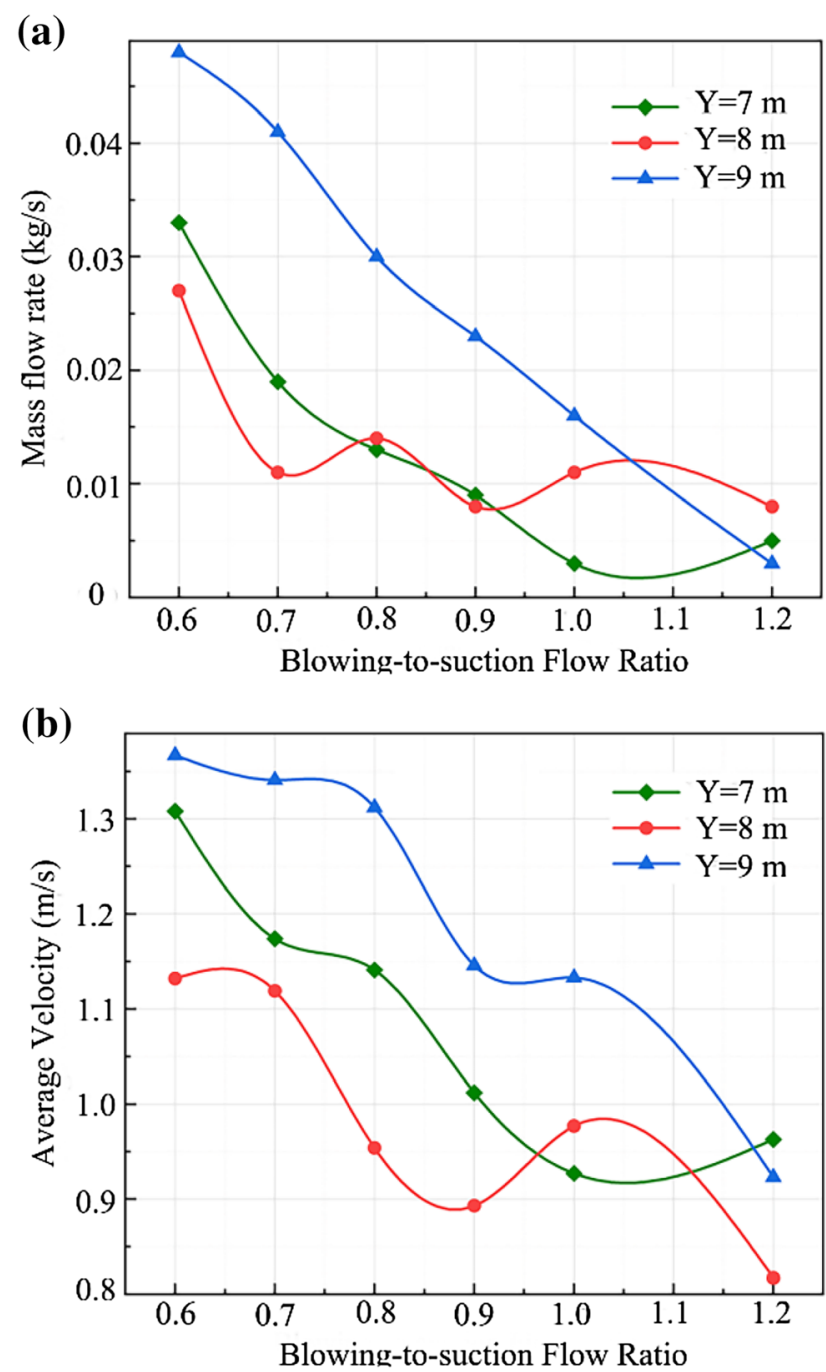

Fig. 15 Impact of the blowing-to-suction flow ratio on the a mass flow rate and $\mathbf{b}$ mean airflow velocity at three different test surfaces

At a blowing-to-suction flow ratio of 0.8 , the air supply capacity of the front face of the supply cylinder increased, which caused a stronger disturbance on the dust around the heading end. The energy of the circulating air in the vortex region further increased. Moreover, the increased air supply capacity around the front face of the supply cylinder moved the produced vortex region away from the heading end and closer to the air exhaust inlet, which enhanced the dust collection effect at the exhaust inlet and resulted in a lower dust concentration around the heading end, as shown in Fig. 16c. Meanwhile, the radial air curtain had an even greater intensity. Although the intensity of the axial air curtain dropped to a certain degree, the integrated impact from both the axial and radial air curtains was optimal. In these conditions, dust was retained in the region around the heading end and was discharged due to the suction airflow. Therefore, the dust diffusion distance was the shortest and the dust concentration around the operational area of the driver was the lowest.

As the blowing-to-suction flow ratio increased to 0.9, 1.0 , and 1.2, the jet velocity from the front area of the air supply cylinder increased, which excessively disturbed the dust around the working face. As a result, dust particles were driven by the airflow and spread outwards. Meanwhile, as shown in Figs. 16d-f, decreases in the axial air curtain intensity weaken the dust barrier effect, and the dust concentration in the driver operating region increases. At a high blowing-to-suction flow ratio such as $\beta=1.2$, dust particles can diffuse as far as $16 \mathrm{~m}$ away and towards the rear of the roadway.

\subsubsection{Three-dimensional (3D) spatial distribution pattern of dust concentration in tunnel}

A 3D graph can provide an intuitive understanding of the dust concentration distribution patterns, which is helpful to investigate the 3D spatial distributions of the parameters. In field production, the dust concentration in the roadheader driver operating area significantly affects operational safety. In this study, the position of the roadheader driver was $5 \mathrm{~m}$ away from the heading end, and the respiratory height of the driver was $1.6 \mathrm{~m}(Z=1.6 \mathrm{~m})$.

As shown in Fig. 17, at a blowing-to-suction flow ratio of 0.6 , the maximum dust diffusion distance was $15 \mathrm{~m}$, and the dust concentration in the driver area $(Y=5 \mathrm{~m})$ was as high as $800 \mathrm{mg} / \mathrm{m}^{3}$. More importantly, the high dust concentration at $Y=1.5 \mathrm{~m}$ significantly affects the driver's operational vision. As the blowing-to-suction flow ratio increased to 0.7 and 0.8 , the dust diffusion distance significantly shortened and the dust concentration at the driver position was reduced to approximately $200 \mathrm{mg} / \mathrm{m}^{3}$. Moreover, at a blowing-to-suction flow ratio of 0.8 , the dust concentration at the operating position was smaller than at 0.7. As the blowing-to-suction flow ratio further increased, the dust diffusion distance began increasing and the dust concentration around the driver started to increase. This is unfavorable for the safe production and operation of the roadheader driver. Based on the analysis, the diffusion rules for dust in a 3D tunnel were nearly the same as the dust diffusion rules at the breathing height of the roadheader driver.

\subsubsection{Dust-blocking efficiency of generated air curtain}

Respiratory dust can cause the occurrence of pneumoconiosis. The proportion of respiratory dust is an important index to evaluate the performance of dust suppression techniques. The statistical analysis of particle sizes at the roadheader driver operating position was performed using Fluent. The proportions of respiratory dust and non- 


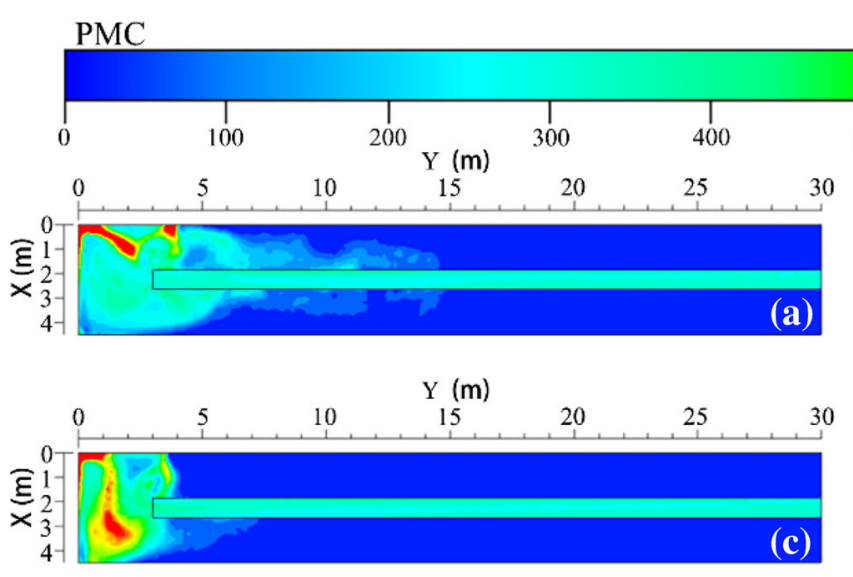

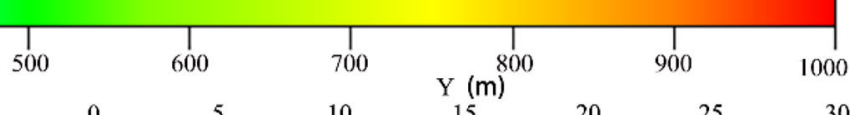
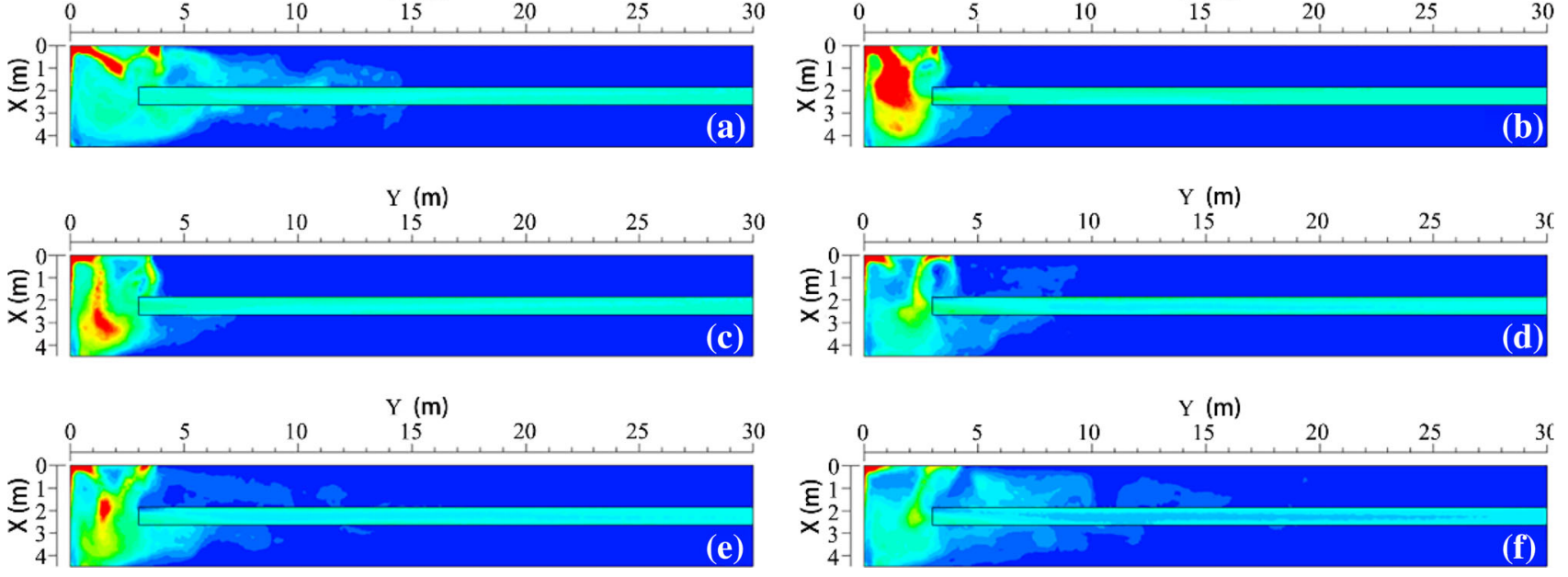

Fig. 16 Concentration distribution patterns of dust on the section located at $Z=1.6 \mathrm{~m}$ at blowing-to-suction flow ratios of $\mathbf{a} \beta=0.6, \mathbf{b} \beta=0.7$, c $\beta=0.8$, d $\beta=0.9$, e $\beta=1.0$, and $\mathbf{f} \beta=1.2$
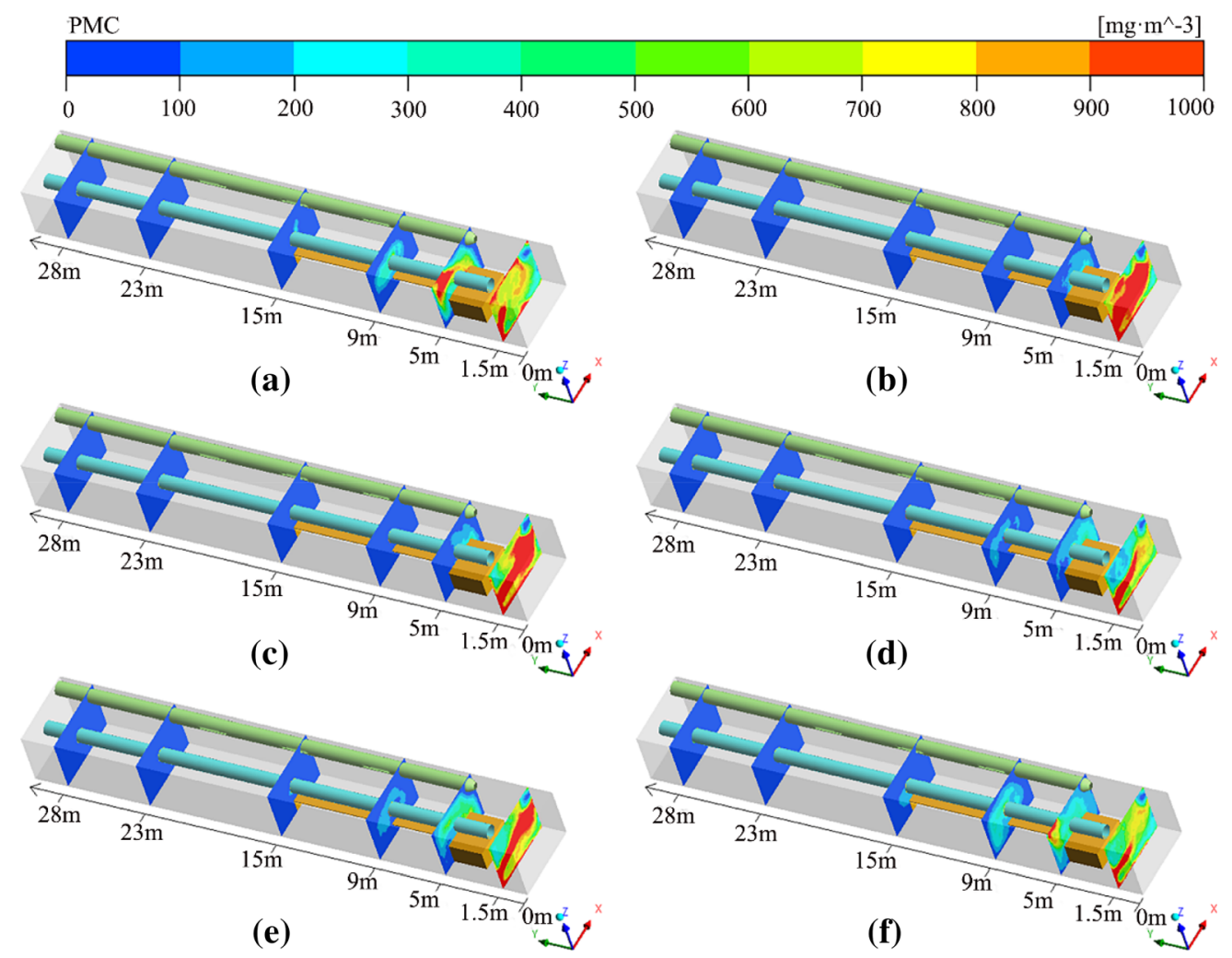

Fig. $173 \mathrm{D}$ graphs for the dust concentration distribution in the tunnel for blowing-to-suction flow ratios of $\mathbf{a} \beta=0.6, \mathbf{b} \beta=0.7$, $\beta=0.8$, d $\beta=0.9$, e $\beta=1.0$, and f $\beta=1.2$

respiratory dust at the driver operating position at varying blowing-to-suction flow ratios were obtained, as shown in Fig. 18.
As shown in Fig. 18a, at a blowing-to-suction flow ratio of 0.8 , the respiratory dust had the lowest proportion $(8.86 \%)$ of total dust around the roadheader driver. As a result, the wall-mounted swirling ventilation system 

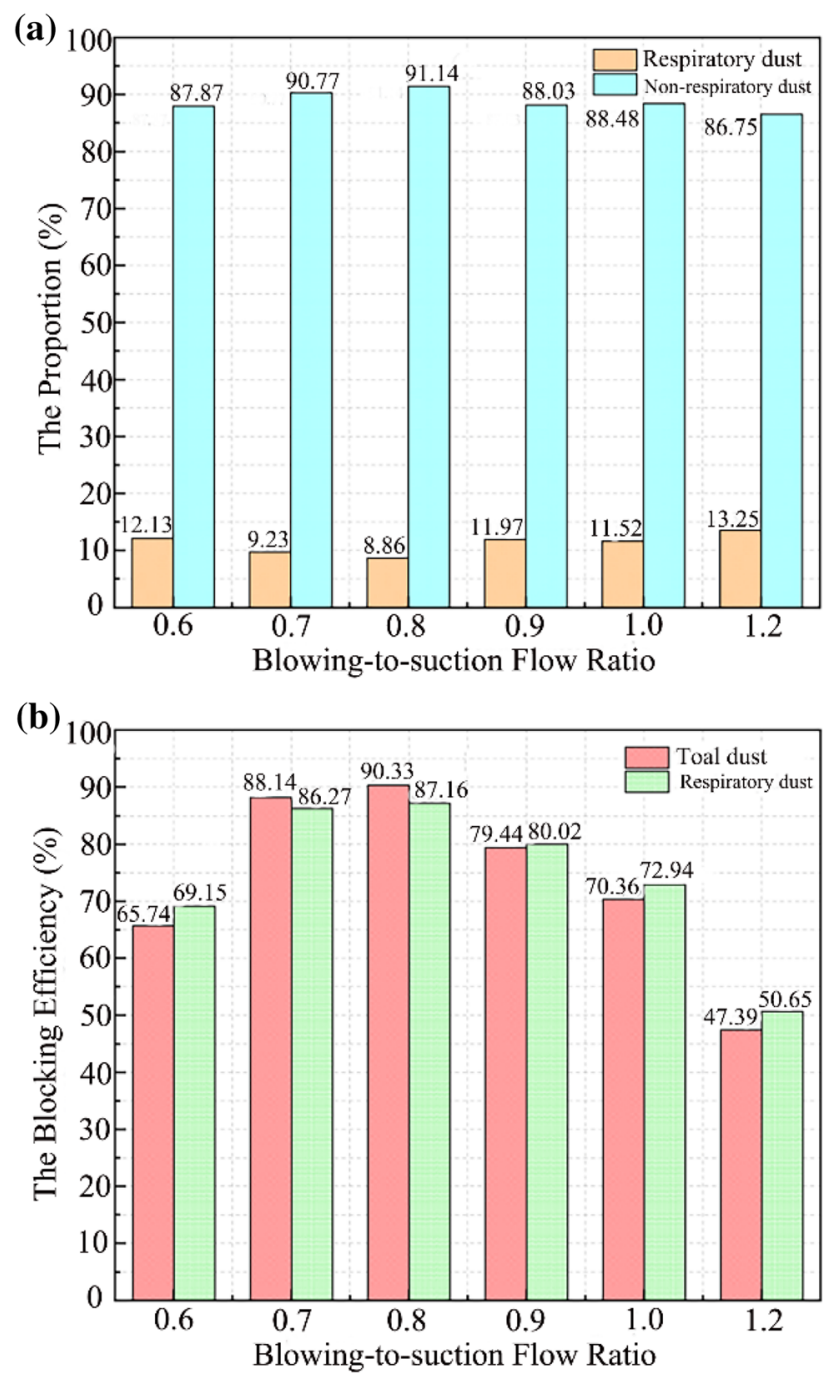

Fig. 18 a Proportions of the respiratory dust and non-respiratory dust and $\mathbf{b}$ a histogram of the dust-blocking efficiencies for both total dust and respiratory dust in the driver operating area at varying blowingto-suction flow ratios

achieved the most favorable dust suppression performance. Thus, the lowest concentrations of both the total dust and respiratory dust around the driver were achieved. Due to the comprehensive effects from the radial and axial air curtains, the strongest dust suppression capability was achieved and the dust concentration distribution in the mining face was ideal. The dust concentrations at the two cross-sections of $Y=1 \mathrm{~m}$ and $Y=5 \mathrm{~m}$ (around the heading end and at the driver operating position) were analyzed to calculate the dust-suppression efficiency of the generated air curtain at each blowing-to-suction flow ratio, as shown in Fig. 18b. The most ideal dust-suppression performance was achieved at a blowing-to-suction flow ratio of 0.8 , which is consistent with the above conclusion. The highest blocking efficiencies for the total dust and respiratory dust were obtained at $90.33 \%$ and $87.16 \%$, respectively.

\section{Conclusions}

A numerical model was developed based on the No. C103 mechanized excavation face at the Nahe Coal Mine in the Baise Mining Bureau, Guangxi. The feasibility of the established model was verified through experiments, which showed the simulation model can precisely reflect the actual operating conditions in the tunnel. Finally, the effects of the blowing-to-suction flow ratio of the wallmounted swirling ventilation system on the airflow field structure and the dust suppression performance were systematically investigated numerically, and the optimal blowing-to-suction flow ratio was obtained. The analysis results indicate that as the blowing-to-suction flow ratio increases, disturbances on the airflow field around the heading end increase and the intensity of the axial air curtain weakens. On the other hand, the intensity of the radial air curtain increases, and the dust-blocking capability is enhanced. At a blowing-to-suction flow ratio of 0.8 , the lowest concentrations of both the total dust and respiratory dust are achieved and the highest blocking efficiencies for both types are obtained at $90.33 \%$ and $87.16 \%$, respectively. Therefore, the optimal dust suppression performance for the wall-mounted swirling ventilation system is achieved at the blowing-to-suction flow ratio of 0.8 . The physical model and boundary conditions are simplified for the numerical simulations, and there may be some deviations between the calculation results and actual conditions. Therefore, the best blowing-to-suction flow ratio needs to be verified in the field. However, for the set working conditions are set, only six blowing-to-suction flow ratios were selected, and the best value is only an approximation; the exact value is yet to be determined.

Acknowledgements Financial support for this work was provided by the National Natural Science Foundation of China (No. 51574123), and the Scientific Research Project of Hunan Province Office of Education (No. 18A185), which are gratefully acknowledged.

Open Access This article is licensed under a Creative Commons Attribution 4.0 International License, which permits use, sharing, adaptation, distribution and reproduction in any medium or format, as long as you give appropriate credit to the original author(s) and the source, provide a link to the Creative Commons licence, and indicate if changes were made. The images or other third party material in this article are included in the article's Creative Commons licence, unless indicated otherwise in a credit line to the material. If material is not included in the article's Creative Commons licence and your intended use is not permitted by statutory regulation or exceeds the permitted use, you will need to obtain permission directly from the copyright holder. To view a copy of this licence, visit http://creativecommons. org/licenses/by/4.0/. 


\section{References}

Aminossadati, SM, Hooman K (2008). Numerical simulation of ventilation air flow in underground mine workings. Proceedings of the 12th North American Mine Ventilation Symposium, 253-259

Amyotte PR, Pegg MJ, Khan FI (2009) Application of inherent safety principles to dust explosion prevention and mitigation. Process Saf Environ Prot 87:35-39. https://doi.org/10.1016/j.psep.2008. 06.007

Camelli F, Byrne G, Lohner R (2014) Modeling subway air flow using CFD. Tunn Undergr Space Technol 43:20-31. https://doi. org/10.1016/j.tust.2014.02.012

Cheng WM, Yu HM, Zhou G, Nie W (2016) The diffusion and pollution mechanisms of airborne dusts in fully-mechanized excavation face at mesoscopic scale based on CFD-DEM. Process Saf Environ Prot 104:240-253. https://doi.org/10.1016/j. psep.2016.09.004

Ciocanea A, Dragomirescu A (2013) Modular ventilation with twin air curtains for reducing dispersed pollution. Tunn Undergr Space Technol 37:180-198. https://doi.org/10.1016/j.tust.2013. 03.012

Fu JW, Liu RH, Wang PF (2008) Discussion on mechanism of vortex ventilation in mechanized excavation face. $\mathrm{J}$ Xiangtan Norm Univ (Nat Sci Ed) 30(1):50-53

Goldasteh I, Ahmadi G, Ferro AR (2013) Monte carlo simulation of micron size spherical particle removal and resuspension from substrate under fluid flows. J Aerosol Sci 66:62-71. https://doi. org/10.1016/j.jaerosci.2013.07.012

Hamid RN, Hassan BT (2013) Development of boundary transfer method in simulation of gas-solid turbulent flow of a riser. Appl Math Model 37:2445-2459. https://doi.org/10.1016/j.apm.2012. 05.030

Hua Y, Nie W, Cai P, Liu YH, Peng HT, Liu Q (2018) Pattern characterization concerning spatial and temporal evolution of dust pollution associated with two typical ventilation methods at fully mechanized excavation faces in rock tunnels. Powder Technol 334:117-131. https://doi.org/10.1016/j.powtec.2018.04. 059

Jiang ZA, Yan P, Chen JS, Zhang ZY (2015) Optimization on parameters of long distance forced and short distance ventilation system in mine rock heading roadway. Coal Sci Technol 43:54-58 https://doi.org/https://doi.org/10.13199/j.cnki.cst. 2015.01.013.

Kim SE, Choudhury D, Patel B (1997) Computations of Complex Turbulent Flows Using the Commercial Code ANSYS Fluent. Modeling Complex Turbulent Flows 259-276. https://doi.org/ https://doi.org/10.1007/978-94-011.

Li M, Aminossadati SM, Wu C (2016) Numerical simulation of air ventilation in super-large underground developments. Tunn Undergr Space Technol 52:38-43. https://doi.org/10.1016/j.tust. 2015.11.009

Li YJ, Wang PF, Liu RH, Gao RZ (2019) Optimization of structural parameters and installation position of the wall-mounted air cylinder in the fully mechanized excavation face based on CFD and orthogonal design. Process Saf Environ Prot 130:344-358. https://doi.org/10.1016/j.psep.2019.08.027

Li YJ, Wang PF, Liu RH, Jiang YD, Han H (2020) Determination of the optimal axial-to-radial flow ratio of the wall-mounted swirling ventilation in fully mechanized excavation face. Powder Technol 360:890-910. https://doi.org/10.1016/j.powtec.2019.10. 067

Liu Q, Nie W, Hua Y, Peng HT, Liu ZQ (2018) The effects of the installation position of a multi-radial swirling air-curtain generator on dust diffusion and pollution rules in a fully-mechanized excavation face: A case study. Powder Technol 329:371-385. https://doi.org/10.1016/j.powtec.2018.01.064

Liu RL, Cheng WM, Yu YB, Xu QF, Jiang AW, Lv T (2019) An impacting factors analysis of miners' unsafe acts based on HFACS-CM and SEM. Process Saf Environ Prot 122:221-231. https://doi.org/10.1016/j.psep.2018.12.007

Liu ZQ, Nie W, Peng HT, Yang SB, Chen DW, Liu Q (2019) The effects of the spraying pressure and nozzle orifice diameter on the atomizing rules and dust suppression performances of an external spraying system in a fully-mechanized excavation face. Powder Technol 350:62-80. https://doi.org/10.1016/j.powtec. 2019.03.029

Liu Q, Nie W, Hua Y, Jia LB, Li CS, Ma H, Wei CH, Liu CQ, Zhou WJ, Peng HT (2019) A study on the dust control effect of the dust extraction system in TBM construction tunnels based on CFD computer simulation technology. Powder Technol, Adv. https://doi.org/10.1016/j.apt.2019.06.019

Liu K, Jia LY, Hao RL, Hao RL, Fu D (2019) A novel CFD-based method for predicting pressure drop and dust cake distribution of ceramic filter during filtration process at macro-scale. Powder Technol 353:27-40. https://doi.org/10.1016/j.powtec.2019.05. 014

Ma YL, Zhou G, Ding JF, Li SL, Wang G (2018) Preparation and characterization of an agglomeration-cementing agent for dust suppression in open pit coal mining. Cellulose 25:4011-4029. https://doi.org/10.1007/s10570-018-1826-z

Nie W, Ma X, Cheng WM, Liu YH, Lin X, Peng HT, Wei WL (2016) A novel spraying/negative-pressure secondary dust suppression device used in fully mechanized mining face: A case study. Process Saf Environ Protect 103:126-135. https://doi.org/10. 1016/j.psep.2016.07.003

Nie W, Wei WL, Cai P, Liu ZQ, Liu Q, Ma H, Liu HJ (2018) Simulation experiments on the controllability of dust diffusion by means of multi-radial vortex airflow. Adv Powder Technol 29:835-847. https://doi.org/10.1016/j.apt.2017.12.027

Parra MT, Villafruela JM, Castro F, Méndez C (2006) Numerical and experimental analysis of different ventilation systems in deep mines. Build Environ 41:87-93. https://doi.org/10.1016/j.buil denv.2005.01.002

Peng HT, Nie W, Cai P, Liu Q, Liu ZQ, Yang SB (2019) Development of a novel wind-assisted centralized spraying dedusting device for dust suppression in a fully mechanized mining face. Environ Sci Pollut Res 26:3292-3307. https://doi. org/10.1007/s11356-018-3264-8

Qin YP, Zhang MM, Cui LJ, Liu JY (2011) Numerical simulation of dust migration and study on dust removal modes with the forced ventilation shunt in a fully mechanized workface. J Univ Sci Technol 33:790-794. https://doi.org/10.13374/j.issn1001-053x. 2011.07.008.

Tan B, Liu H, Xu B, Wang T (2020) Comparative study of the explosion pressure characteristics of micro- and nano-sized coal dust and methane-coal dust mixtures in a pipe. Int $\mathrm{J}$ Coal Sci Technol 7(1):68-78

Tan C, Jiang ZA, Wang M, Chen Y, (2015). Similarity experiment on multi-source dust diffusion law in fully mechanized caving face. China Coal Soc. 40(1):122-127. https://doi.org/10.13225/j.cnki. jecs.2014.0105.

Tao M, Zhao HT, Li XB, Li X, Du K (2018) Failure characteristics and stress distribution of pre-stressed rock specimen with circular cavity subjected to dynamic loading. Tunn Undergr Space Technol 81:1-15. https://doi.org/10.1016/j.tust.2018.06. 028

Toraño J, Torno S, Menéndez M, Gent M (2011) Auxiliary ventilation in mining roadways driven with roadheaders: Validated CFD modelling of dust behavior. Tunn Undergr Space Technol 26:201-210. https://doi.org/10.1016/j.tust.2010.07.005 
Van den Berg L, Van den Berg L, Marx WM, Thomson C (2011) Development and integration of ventilation simulation tools for colliery ventilation practice. J Min Vent Soc S Afr 64:16-21

Wang XZ, Yang F, Zhu FS (2002) New technology for coal mine safety, 1st edn. China Coal Industry Publishing House, China

Wang XZ, Jiang ZA, Wang SW, Liu Y (2007) Numerical simulation of distribution regularities of dust concentration during the ventilation process of coal roadway driving. J. China Coal Soc 32(4):386-390. https://doi.org/10.13225/j.cnki.jccs.2007.04.011

Wang YC, Luo G, Geng F, Li YB, Li YL (2015) Numerical study on dust movement and dust distribution for hybrid ventilation system in a laneway of coal mine. J Loss Prev Process Ind 36:146-157. https://doi.org/10.1016/j.jlp.2015.06.003

Wang PF, Tan XH, Cheng WM, Guo G, Liu RH (2018a) Dust removal efficiency of high pressure atomization in underground coal mine. Int J Mining Sci Technol 28:312-318

Wang H, Nie W, Cheng WM, Liu Q, Jin H (2018b) Effects of air volume ratio parameters on air curtain dust suppression in a rock tunnel's fully-mechanized working face. Adv Powder Technol 29:230-244. https://doi.org/10.1016/j.apt.2017.11.007

Wang JY, Zhou G, Wei X, Wang SC (2019a) Experimental characterization of multi-nozzle atomization interference for dust reduction between hydraulic supports at a fully mechanized coal mining face. Environ Sci Pollut Res 26:10023-10036. https://doi.org/10.1007/s11356-019-04413-w

Wang HT, Du YH, Wei XB, He XX (2019b) An experimental comparison of the spray performance of typical water-based dust reduction media. Powder Technol 345:580-588. https://doi.org/ 10.1016/j.powtec.2019.01.032

Wang PF, Tian C, Liu RH, Wang J (2019c) Mathematical model for multivariate nonlinear prediction of SMD of X-type swirl pressure nozzles. Process Saf Environ Prot 125:228-237. https://doi.org/10.1016/j.psep.2019.03.023

Wang HT, Xuan WF, Zhang ZZ, Qin BT (2019d) Experimental investigation of the properties of dust suppressants after magnetic-field treatment and mechanism exploration. Powder Technol 342:149-155. https://doi.org/10.1016/j.powtec.2018.09. 099

Wang PF, Zhang K, Liu RH (2019e) Influence of air supply pressure on atomization characteristics and dust-suppression efficiency of internal-mixing air-assisted atomizing nozzle. Powder Technol 355:393-407. https://doi.org/10.1016/j.powtec.2019.07.040

Wang PF, Shi YJ, Zhang LY, Li YJ (2019f) Effect of structural parameters on atomization characteristics and dust reduction performance of internal-mixing air-assisted atomizer nozzle. Process Saf Environ Prot 128:316-328. https://doi.org/10.1016/j. psep.2019.06.014

Wang PF, Li YJ, Liu RH, Shi YJ (2019g) Effects of forced-to-exhaust ratio of air volume on dust control of wall attached swirling ventilation for mechanized excavation face. Tunn Undergr Sp Technol 90:194-207. https://doi.org/10.1016/j.tust.2019.04.026

Wang HT, Wei XB, Du YH, Wang DM (2019h) Experimental investigation on the dilatational interfacial rheology of dustsuppressing foam and its effect on foam performance. Process Saf Environ Protect 123:351-357. https://doi.org/10.1016/j.psep. 2019.01.027

Wang YP, Jiang ZA, Chen JS, Chen JH, Wang M (2019i) Study of high-pressure air curtain and combined dedusting of gas water spray in multilevel ore pass based on CFD-DEM. Adv Powder Technol 30:1789-1804. https://doi.org/10.1016/j.apt.2019.05. 019

Widiatmojo A, Sasaki K, Sugai Y, Suzuki Y, Tanaka H, Uchida K, Matsumoto H (2015) Assessment of air dispersion characteristic in underground mine ventilation: Field measurement and numerical evaluation. Process Saf Environ Protect 93:173-181. https://doi.org/10.1016/j.psep.2014.04.001

Yao W, Pang J, Ma Q, Lyimo H (2020) Influence and sensitivity analysis of thermal parameters on temperature field distribution of active thermal insulated roadway in high temperature mine. Int J Coal Sci Technol. https://doi.org/10.1007/s40789-02000343-y

Yin S, Nie W, Liu Q, Hua Y (2019) Transient CFD modelling of space-time evolution of dust pollutants and air-curtain generator position during tunneling. J Clean Prod. https://doi.org/10.1016/ j.jclepro.2019.117924

Zhang ZJ, Yuan YP, Wang KQ, Gao XK, Cao XL (2016) Experimental investigation on influencing factors of air curtain systems barrier efficiency for mine refuge chamber, Process Saf. Environ Protect 102:534-546. https://doi.org/10.1016/j.psep. 2016.05.008

Zhang HH, Nie W, Wang HK, Bao Q, Jin H, Liu YH (2018) Preparation and experimental dust suppression performance characterization of a novel guar gum-modification-based environmentally-friendly degradable dust suppressant. Powder Technol 339:314-325. https://doi.org/10.1016/j.powtec.2018.08.011

Zhou FB, Li JL, Li SH, Wang F (2017) Experimental investigation and application of dry-type filtering dust collection technology in fully mechanized excavation face. J China Coal Soc 42(3):639-645. https://doi.org/10.13225/j.cnki.jccs.2016.1150

Zhou WJ, Nie W, Liu CQ, Liu Q, Wang HT, Wei CH, Yan JY, Yin S, Xiu $\mathrm{ZH}, \mathrm{Xu} \mathrm{CW}$ (2019a) Modelling of ventilation and dust control effects during tunnel construction. Int $\mathrm{J}$ Mech Sci 160:358-371. https://doi.org/10.1016/j.ijmecsci.2019.06.037

Zhou Q, Qin BT, Wang F, Wang HT, Hou J, Wang ZR (2019b) Effects of formation patterns on the atomization characteristics of a dust removal spray on the coal cutter. Powder Technol 344:570-580. https://doi.org/10.1016/j.powtec.2018.12.021 